\title{
Proteomic analysis of A2780/S ovarian cancer cell response to the cytotoxic organogold(III) compound Aubipyc
}

\author{
Tania Gamberi ${ }^{a}$, Lara Massai ${ }^{b}$, Francesca Magherini ${ }^{a}$, Ida Landini ${ }^{c}$, Tania Fiaschi $^{a}$, \\ Federica Scaletti ${ }^{b}$, Chiara Gabbiani ${ }^{d}$, Laura Bianchi ${ }^{e}$, Luca Bini ${ }^{e}$, Stefania Nobilic, \\ Gabriele Perrone ${ }^{c}$, Enrico Mini ${ }^{c}$, Luigi Messori ${ }^{b, *}$, Alessandra Modesti ${ }^{a, * *}$ \\ ${ }^{a}$ Department of Clinical and Preclinical Biomedical Sciences, University of Florence, Italy \\ ${ }^{b}$ Department of Chemistry, University of Florence, Italy \\ ${ }^{c}$ Department of Health Sciences, Section of Clinical Pharmacology and Oncology, University of Florence, Italy \\ ${ }^{\mathrm{d}}$ Department of Chemistry and Industrial Chemistry, University of Pisa, Italy \\ ${ }^{\mathrm{e}}$ Functional Proteomic Section, Department of Life Sciences, University of Siena, Italy
}

\section{A R T I C L E I N F O}

Article history:

Received 8 November 2013

Accepted 24 March 2014

\section{Keywords:}

Gold compounds

Proteomics

Two-dimensional electrophoresis Cancer

\begin{abstract}
A B S T R A C T
Aubipy $_{c}$ is an organogold(III) compound endowed with encouraging anti-proliferative properties in vitro that is being evaluated pre-clinically as a prospective anticancer agent. A classical proteomic approach is exploited here to elucidate the mechanisms of its biological actions in A2780 human ovarian cancer cells. Based on 2-D gel electrophoresis separation and subsequent mass spectrometry identification, a considerable number of differentially expressed proteins were highlighted in A2780 cancer cells treated with Aubipy. Bioinformatic analysis of the groups of up-regulated and down-regulated proteins pointed out that Aubipy $y_{c}$ primarily perturbs mitochondrial processes and the glycolytic pathway. Notably, some major alterations in the glycolytic pathway were validated through Western blot and metabolic investigations.
\end{abstract}

Biological significance

This is the first proteomic analysis regarding Aubipy ${ }_{c}$ cytotoxicity in A2780/S ovarian cancer cell line. Aubipy $y_{c}$ is a promising gold(III) compound which manifests an appreciable cytotoxicity toward the cell line A2780, being able to overcome resistance to platinum. The

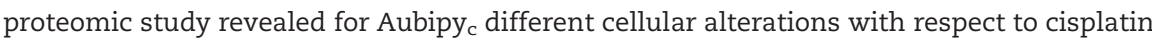
as well as to other gold compound such as auranofin. Remarkably, the bioinformatic analysis of proteomic data pointed out that Aubipyc treatment affected, directly or indirectly, several glycolytic enzymes. These data suggest a new mechanism of action for this gold drug and might have an impact on the use of gold-based drug in cancer treatment.

(c) 2014 Elsevier B.V. All rights reserved.

\footnotetext{
* Correspondence to: L. Messori, Department of Chemistry "Ugo Schiff”, University of Florence, Via della Lastruccia, 3-13, 50019 Sesto Fiorentino, Florence, Italy. Tel.: +39 0554573388; fax: +39 0554573385.

** Correspondence to: A. Modesti, Department of Clinical and Preclinical Biomedical Sciences Biochemistry, University of Florence, Viale Morgagni 50, 50134 Florence, Italy. Tel.: + 39 0552751237; fax: + 390554598905.

E-mail addresses: luigi.messori@unifi.it (L. Messori), alessandra.modesti@unifi.it (A. Modesti).
} 


\section{Introduction}

Metal-based agents, and more specifically platinum drugs, play a major role in current chemotherapeutic regimens for cancer treatment [1]. Nonetheless, the clinical use of platinum drugs is still heavily limited by a high systemic toxicity and by the frequent occurrence of intrinsic or acquired resistance [2]. This triggered the search of other families of anticancer drugs based on metals different from platinum, e.g. ruthenium, tin and copper [3]. Nowadays, gold compounds offer an effective and innovative alternative to platinum drugs and are therefore intensively investigated [4]. Interest in gold compounds is also fuelled by the observation that they usually manifest a very different pharmacological profile compared to established anticancer platinum drugs implying the occurrence of original and innovative modes of action and the chance to overcome platinum resistance $[5,6]$. Hence, over the last two decades, several promising families of Au-based drug candidates, with the gold center in the oxidation state +3 or +1 , featuring diverse structural motifs, were prepared, characterized and their biological and pharmacological profiles initially assessed $[7,8]$. Relevant examples are offered by a few classical mononuclear gold(III) complexes [9] such as gold(III) dithiocarbamates [10] and gold(III) porphyries [11]; by some organogold(III) compounds [12,13]; a few binuclear gold(III) complexes [14]; various neutral, two-coordinate gold(I) complexes [15], inspired to auranofin; a number of lyophilise cationic gold(I) complexes such as [Au(dope)2]+, and others.

Compounds were mainly driven by their chemical analogy with platinum(II)-based drugs [6]. It was postulated that the biological effects of gold(III) compounds might be a consequence of direct DNA damage as for cisplatin and its analogs. However, in contrast to general expectations, a number of subsequent studies suggested that gold(III) compounds exert their cytotoxicity and antiproliferative effects mainly through DNA independent mechanisms [16]. Notably, it has been shown that these gold(III) compounds are able to trigger apoptosis by a direct mitochondrial damage $[1,12,17,18]$. Also, there are suggestions that a few peculiar proteins such as thioredoxin reductase, the proteasome or the nuclear factor $\mathrm{kb}$ (NF-kb) system may constitute major targets for these gold compounds [1,18-20].

Aubipy $_{c}$ is a promising gold(III) compound that was characterized chemically and biologically through a few recent studies [21,22]. It consists of a square planar gold(III) center receiving three donors - i.e. C, N, N - from the tridentate bipyridyl ligand while the fourth coordination position is occupied by a hydroxide group (Fig. 1); the latter is the preferential site for ligand replacement reaction and for protein biding. Aubipy ${ }_{c}$ is acceptably stable under physiological conditions even in the presence of reducing agents. Previous studies revealed that Aubipy $_{c}$ manifests an appreciable cytotoxicity toward the human ovarian cancer cell line A2780, being able to overcome resistance to platinum. Moreover, it was found that Aubipyc induces apoptotic cell death [21]. Since this gold compound is a strong inhibitor of thioredoxin reductase, it was hypothesized that cell death proceeds through apoptosis possibly as a consequence of a direct mitochondrial damage [23]. However, details of the molecular mechanism leading to mitochondrial

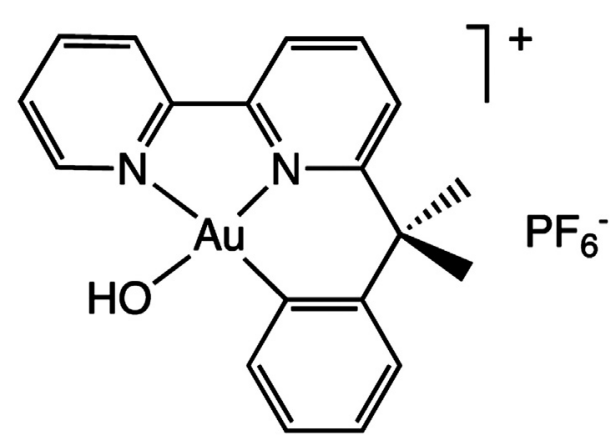

Fig. 1 - Chemical structure of Aubipyc.

damage and consequent induction of apoptosis remain unexplored and warrant further studies.

Here we have adopted a proteomic approach to better characterize the mechanism of action of Aubipy. Proteomics is today a very powerful investigation tool of cellular processes providing detailed and direct insight into the fine alterations in cell homeostasis induced by exposure to drugs and xenobiotics. Such alterations occurring at the level of several intracellular signaling and metabolic pathways may tell us which parts of the complex cellular machinery are mainly affected by treatment, also suggesting which parts are the most probable biomolecular targets for a specific compound. Previous studies well documented the application of proteomic approaches to the study of the mechanism of various anticancer metal-based drugs [24]. Studies on platinum compounds revealed cellular responses induced by cisplatin treatment and also disclosed the molecular basis for platinum resistance $[25,26]$. On the other hand, a number of studies on the proteomic effects of selected gold compounds illustrated the complex responses elicited in cancer cells, highlighting the role of specific defense systems. Some interesting hypotheses were made concerning the likely antiproliferative mechanisms of some gold compounds. Relevant changes in the expression of a number of proteins engaged in redox metabolism, stress response, in mitochondrial functions as well as in apoptosis pathways were detected [11,27]. In previous works we obtained proteomic results for the gold(III) compound Auoxo6 and Auranofin on A2780 cell line, either sensitive (A2780/S) or resistance (A2780/R) to cisplatin. Concerning the A2780/S, the results pointed out that the mode of action of Auoxo6 is strictly related to that of auranofin. Both gold compounds trigger caspase 3 activation and apoptosis and the affected proteins are involved in cell redox homeostasis and stress response [28]. Conversely, in the A2780/R cell line, Auranofin affected the expression of proteasome apparatus proteins whereas Auoxo6 modified the expression of proteins related to mRNA trafficking and stability [29]. More recently, we performed a proteomic study on two additional gold compounds, $\mathrm{Au}_{2}$ phen and Aul12 in A2780/S cells. The obtained results were basically in line with those of Auoxo6 and Auranofin in A2780/S cells. We observed few protein expression variations. Moreover, both compounds affected proteins involved in protein synthesis, mRNA splicing and proteins involved in proteasome-mediated protein degradation [30]. However, in all these studies, no underlying mechanism or pathway could be clearly identified. 
The aim of the present study was to characterize the molecular basis of Aubipy cytotoxicity in human ovarian cancer cell line A2780/S. The proteome of treated cells was examined with respect to that of untreated cells, by two-dimensional electrophoresis coupled with mass spectrometry. We identified 87 differentially expressed proteins. Among them, 29 proteins were up-regulated upon Aubipy exposure. Most of these proteins are involved in cellular processes such as stress response, protein synthesis and cytoskeleton and cell structure. Fifty-eight proteins were down-regulated. Most of these proteins belong to glucose metabolism, stress response and cell redox homeostasis.

The alteration on glucose metabolism, in particular of glycolysis, was confirmed by Western blot, bioinformatic analysis and metabolic investigations, such as glucose consuming and the effect of extra pyruvate addition in culture medium on antiproliferative activity of Aubipyc against A2780/S cell line. These data indicate that Aubipyc affects glycolytic pathway. This work therefore offers novel insights, from the prospective of the metabolic response, into

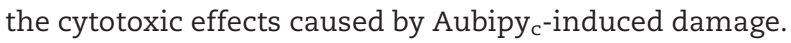

\section{Material and methods}

\subsection{Materials}

RPMI 1640 cell culture medium, fetal calf serum (FCS), and phosphate-buffered saline were obtained from Celbio (Milan, Italy); sulforhodamine B (SRB) and cisplatin were obtained from Sigma (Milan, Italy). All chemicals were purchased from Sigma Aldrich (Italy), unless mentioned otherwise.

\subsection{Cell lines and culture conditions}

The human ovarian carcinoma cell line sensitive to cisplatin (A2780/S) was used for cytotoxicity and proteomic studies. Cells were maintained in RPMI1640 medium supplemented with $10 \%$ of FCS and antibiotics at $37{ }^{\circ} \mathrm{C}$ in a $5 \%$ CO2 atmosphere and sub-cultured twice weekly.

\subsection{Cell growth inhibition studies}

The cytotoxic activity of Aubipy c $_{\mathrm{c}}$ was evaluated against the A2780/S cell line according to the procedure described by Skehan et al. [31]. Briefly, exponentially growing cells were seeded in 96-well microplates for $24 \mathrm{~h}$ prior to the addition of Aubipy $_{c}$. After $24 \mathrm{~h}$, the medium was removed and replaced with fresh medium containing concentrations of Aubipy ranging from 0.003 to $100 \mu \mathrm{M}$. Two different times of exposure to Aubipyc, 24 and 72 h, were used. For comparison purposes the cytotoxicity of cisplatin was evaluated in the same experimental conditions. Then the cells were fixed with trichloroacetic acid and then stained with sulforhodamine B (SRB) solution, rinsed with $0.1 \%$ acetic acid and air-dried. At the end of the staining period, SRB was dissolved in $10 \mathrm{mM}$ Tris- $\mathrm{HCl}$ solution ( $\mathrm{pH}$ 10.5). Optical density was read in a microplate reader interfaced with the software Microplate Manager/PV version 4.0 (Bio-Rad Laboratories, Milan, Italy) at $540 \mathrm{~nm}$. The $\mathrm{IC}_{50}$ drug concentration resulting in a $50 \%$ reduction in the net protein content (as measured by SRB staining) in drug-treated cells as compared with untreated control cells was determined. The IC $_{50}$ drug concentration was also evaluated in medium supplemented with $1 \mathrm{mM}$ pyruvate. The reported $\mathrm{IC}_{50}$ data represent the mean of at least three independent experiments.

\subsection{Trypan blue vital dye exclusion assay}

To evaluate the viability of cells to be used in the proteomic studies, a time course at 24, 48 and $72 \mathrm{~h}$ drug exposures with $3.1 \mu \mathrm{M}$ of Aubipy $_{c}$ (equal to 72-h-exposure IC $_{50}$ value), was performed by trypan blue vital dye exclusion assay. Briefly, $200 \mu \mathrm{L}$ of trypsinized and re-suspended cells were mixed with $200 \mu \mathrm{L}$ of $0.4 \%$ solution of trypan blue dye (Sigma-Aldrich) for $5 \mathrm{~min}$. Numbers of total cells, live cells and dead cells, were immediately counted using a Neubauer micro-chamber (Brand $\mathrm{GmbH}$, Wertheim, Germany) with a light microscope. All counts were done in duplicates of each sample. The reported data represent the mean of three independent experiments.

\subsection{Sample preparation and 2-D gel electrophoresis}

A2780/S cells were seeded in tissue-culture plates at $5 \times 10^{4}$ cells/mL (total volume $30 \mathrm{~mL}$ ) and incubated overnight, then exposed to the concentration of the Aubipyc equal to 72-h-exposure IC $_{50}$ values for $24 \mathrm{~h}(3.1 \mu \mathrm{M})$. Aubipy stock solution was prepared in dimethyl sulfoxide, then A2780/S control cells were treated with an equal concentration of DMSO. At the end of incubation the cells were washed with phosphate-buffered saline and then scraped in RIPA buffer (50 mM Tris-HCl pH 7.0, 1\% (v/v) NP-40, $150 \mathrm{mM} \mathrm{NaCl}, 2 \mathrm{mM}$ ethylene glycol bis(2-aminoethyl ether)tetra-acetic acid, $100 \mathrm{mM} \mathrm{NaF}$ ) containing a human protease inhibitor cocktail (Sigma). The cells were sonicated (15 s) and protein extracts were clarified by centrifugation at $8000 \mathrm{~g}, 4^{\circ} \mathrm{C}$ for $15 \mathrm{~min}$. Proteins were precipitated following a chloroform/methanol protocol [32] and the protein pellets were resolved in a buffer containing $8 \mathrm{M}$ urea, $4 \%(\mathrm{w} / \mathrm{v})$ 3-cholamidopropyl dimethylammonium-1-propane sulfonate (CHAPS), $65 \mathrm{mM}$ dithioerythritol (DTE). Protein concentration was determined by the standard Bradford method (Bio-Rad). Isoelectric focusing (IEF) was carried out on nonlinear widerange immobilized $\mathrm{pH}$ gradient ( $\mathrm{pH}$ 3-10; 18-cm-long IPG strip; Bio-Rad) and achieved using an Ettan IPGphor ${ }^{\mathrm{TM}}$ system (GE Healthcare). Protein sample $(700 \mu \mathrm{g})$ was cup-loaded near the anode in the Ettan IPGphor Cup Loading Manifold ${ }^{\mathrm{TM}}$ (GE Healthcare) after the rehydration of the IPG strips with $350 \mu \mathrm{L}$ of rehydration solution (8 M urea, 2\% (w/v) CHAPS, 0.5\% (w/v) DTE) supplemented with $0.5 \%$ (v/v) carrier ampholyte (Bio-Rad) and a trace of bromophenol blue, overnight at room temperature. The strips were focused at $16{ }^{\circ} \mathrm{C}$ according to the following electrical conditions: $200 \mathrm{~V}$ for $1 \mathrm{~h}, 300 \mathrm{~V}$ for $1 \mathrm{~h}$, from 300 to $3500 \mathrm{~V}$ in $30 \mathrm{~min}, 3500 \mathrm{~V}$ for $4 \mathrm{~h}, 5000$ for $2 \mathrm{~h}$, from 5000 to $8000 \mathrm{~V}$ in $30 \mathrm{~min}$, and $8000 \mathrm{~V}$ until a total of $100,000 \mathrm{~V} / \mathrm{h}$ was reached, with a limiting current of $50 \mu \mathrm{A} /$ strip. After focusing, strips were equilibrated in $6 \mathrm{M}$ urea, $2 \%$ (w/v) SDS, $2 \%$ (w/v) DTE, $30 \%$ (v/v) glycerol and $0.05 \mathrm{M}$ Tris- $\mathrm{HCl} \mathrm{pH} 6.8$ for $10 \mathrm{~min}$ and, subsequently, for $10 \mathrm{~min}$ in the same urea/SDS/Tris-HCl buffer solution where DTE was substituted with $2.5 \%$ (w/v) iodoacetamide (IA). The equilibrated strips were placed on 
top of $9-16 \%$ polyacrylamide linear gradient gels $(18 \mathrm{~cm} \times$ $20 \mathrm{~cm} \times 1.5 \mathrm{~mm}$ ) and embedded in $0.5 \%(\mathrm{w} / \mathrm{v})$ heated low-melting agarose in SDS electrophoresis running buffer (25 mM Tris, $192 \mathrm{mM}$ glycine, 0.1\% (w/v) SDS, pH 8.3). The methylenebisacrylamide was the cross-linker used in the 9-16\% gradient. SDS-PAGE was performed in a PROTEAN II xi cell gel electrophoresis unit (Bio-Rad) at $10^{\circ} \mathrm{C}$ and at $40 \mathrm{~mA} / \mathrm{gel}$ constant current, until the dye front reached the bottom of the gel, according to Hochstrasser et al., [33]. Gels were stained with colloidal Coomassie blue silver [34].

\subsection{Image analysis and statistics}

Three independent Aubipyc treatments were performed (biological replicates) and for each sample two 2-DE gels were carried out (technical replicates), so that 12 gels in total were analyzed ( 6 gels for both A2780/S Aubipy ${ }_{c}$-treated and control cells). Colloidal Coomassie blue silver-stained gels were digitized using the Epson expression 1680 PRO scanner. The gel images were saved with a resolution of $300 \mathrm{dpi}$ and as 16-bit TIFF format. Image analysis was carried out using the Progenesis SameSpots software version 4.0 (Nonlinear Dynamics, UK) which allows spot detection, background subtraction and protein spot volume quantification. The gel image showing the highest number of spots and the best protein pattern was chosen as the reference image and its spots were then matched across all gels. This reference image was used to quantify and normalize the spot volumes. The spot volumes were normalized in each gel as a relative volume (volume percentage), by dividing the raw quantity of each spot by the total quantity of all the spots included in the reference gel. Statistical analysis was performed using default parameters of the Progenesis SameSpots Stat module. The $\log _{10}$-normalized spot volume was used for the analysis as the log transformation improves normality [35]. The univariate data analysis was performed as one-way ANOVA $(p<0.05)$ on each spot individually. Then, a multivariate statistics was applied including a false discovery rate-corrected $p$-value ( $q$-value) and Principal Component Analysis (PCA). Moreover, we performed a power analysis to asses the number of sample replicates that need to be analyzed in order to confidently discover differentially expressed proteins. The accepted power threshold is $\geq 0.8$ [36]. We considered differentially expressed spots those having a $q$-value $\leq 0.05$ and a power $\geq 0.8$. These spots were subjected to mass spectrometry analysis.

\subsection{Mass spectrometry analysis}

Electrophoretic spots were manually excised, destained, and acetonitrile dehydrated. A trypsin solution $(0.25 \mathrm{mg} / \mathrm{mL})$ in $50 \mathrm{mM}$ ammonium bicarbonate was added for in-gel protein digestion by overnight incubation at $37{ }^{\circ} \mathrm{C}$. Solutions containing digested peptides were recovered and $20 \mu \mathrm{L}$ of $1 \%$ TFA $50 \%$ ACN was added to each spot and sonicated for $10 \mathrm{~min}$ to maximize peptide recovery. At the end, all recovered peptide solutions were combined and concentrated for each spot separately. From each protein digest $0.75 \mu \mathrm{L}$ was spotted onto the MALDI target and allowed to air dry at room temperature. Then, $0.75 \mu \mathrm{L}$ of matrix solution (saturated solution of $\alpha$-cyano-4-hydroxycinnamic acid in $50 \%$ (v/v) acetonitrile and $0.5 \%$ (v/v) TFA) was applied to the sample and crystallized by air drying at room temperature for 5 min. Protein identification was carried out by peptide mass fingerprinting (PMF) on an Ultraflex III MALDI-TOF/TOF mass spectrometer (Bruker Daltonics) equipped with a $200 \mathrm{~Hz}$ smartbeam ${ }^{\text {TM }}$ I laser. MS analysis was performed in the positive reflector mode according to defined parameters, as follows: 80 ns of delay; ion source 1: $25 \mathrm{kV}$; ion source 2: $21.75 \mathrm{kV}$; lens voltage: $9.50 \mathrm{kV}$; reflector voltage: $26.30 \mathrm{kV}$; and reflector 2 voltage: $14.00 \mathrm{kV}$. The applied laser wavelength and frequency were $353 \mathrm{~nm}$ and $100 \mathrm{~Hz}$, respectively, and the percentage was set to $46 \%$. Final mass spectra were produced by averaging 1500 laser shots targeting five different positions within the spot. Spectra were acquired automatically and the Flex Analysis software version 3.0 (Bruker) was used for their analysis and for the assignment of the peaks. The applied software generated a list of peaks up to 200, using a signal-to-noise ratio of 3 as threshold for peak acceptance. Recorded spectra were calibrated using, as an internal standard, peptides arising from trypsin auto-proteolysis. The mass lists were filtered for contaminant removal: mass matrix-related ions, trypsin auto-lysis and keratin peaks. Protein identification by Peptide Mass Fingerprint search was established using MASCOT search engine version 2.1 (Matrix Science, London, UK, http://www.matrixscience. com) through the UniProtKB database (http://www.uniprot. org/). Taxonomy was limited to Homo sapiens, a mass tolerance of 100 ppm was allowed, and the number of accepted missed cleavage sites was set to one. Alkylation of cysteine by carbamidomethylation was considered a fixed modification, while oxidation of methionine was considered as a possible modification. The criteria used to accept identifications included the extent of sequence coverage, the number of matched peptides, and a probabilistic score at $p<0.05$.

\subsection{Western blot analysis}

A2780/S cells were treated for 24 and $48 \mathrm{~h}$ with Aubipyc concentration corresponding to its 72 -h-exposure IC $_{50}$ dose $(3.1 \mu \mathrm{M})$. Protein preparation was the same as those of the 2-D experiments. Protein samples $(30 \mu \mathrm{g})$ were separated on $4-$ $16 \%$ gradient SDS-PAGE precast gels (Biorad) and transferred onto a PVDF membrane (Millipore). The relative amount of the GAPDH, PGK1, ENO1 and PKM was assessed with appropriate monoclonal antibodies (Santa Cruz Biotechnology). According to datasheets, all antibodies were employed with a 1:1000 dilution in $2 \%$ milk. After incubation with horseradish peroxidase (HRP)-conjugated anti-mouse IgG (1:2000) (Amersham Biosciences), immune complexes were detected with the enhanced chemiluminescence (ECL) detection system (Amersham Biosciences). The membranes were exposed to autoradiographic films (Hyperfilm MP; Amersham Biosciences) for 1-30 min. For quantification, blots were subjected to densitometric analysis using Quantity One Software (Bio-Rad). The intensity of the immunostained bands was normalized with the total protein intensities measured by Coomassie brilliant blue R-250 from the same blot. Statistical analysis, of three independent experiments, was performed by two-tailed non-paired Student's-t-test using Graphpad Prism 4. A $p$-value $<0.05$ was considered statistically significant. 


\subsection{Glucose assay}

A2780/S cells were treated for $48 \mathrm{~h}$ with Aubipy ${ }_{c}$ concentration corresponding to its 72-h-exposure $\mathrm{IC}_{50}$ dose $(3.1 \mu \mathrm{M})$. One milliliter of medium supernatant was harvested immediately

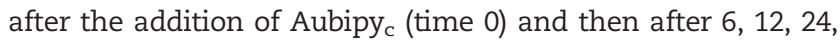
$48 \mathrm{~h}$. Glucose concentration was measured using commercially kit based on the glucose oxidase/peroxidase enzymic procedure (K-GLUC from Meganzyme). Experiments were performed in triplicate. A two-tailed non-paired Student's-t-test was performed using Graphpad Prism 4. A p-value $<0.05$ was considered statistically significant.

\subsection{Bioinformatic functional analysis}

To identify statistically over-represented (enriched) Gene Ontology terms among the differentially expressed proteins identified by MS analysis, we used David Bioinformatics Resource (version 6.7) (Database for Annotation, Visualization and Integrated Discovery; http://david.abcc.ncifcrf.gov/). The differentially expressed proteins identified by MS were divided in two lists: one containing the up-regulated proteins and one containing the down regulated proteins. These lists were compiled reporting UniProtKB accession number. Fisher's exact test was used to check for significant over-representation $(p<0.05)$ of GO terms in the submitted dataset against the H. sapiens genome. Furthermore Benjamini multiple testing was performed to globally correct the $p$-value controlling family-wide false discovery rate $(p$-value $\leq 0.1)$.

To perform network analysis we used the free-web portal BioProfiling.de (http://www.BioProfiling.de). It provides a common interface for the collection of recently developed tools [37]; description and details of the tools can be found in original publications [38]. The gene/protein list is profiled with respect to the most information available regarding gene function, protein interactions, pathway relationships, in silico predicted microRNA to gene associations, as well as, information collected by text mining. The network analysis used has been freely available web-based tool for the interpretation of experimentally derived protein lists in the context of a global PPI network. We uploaded a dataset containing the Uniprot Accession of all the identified proteins. The significantly enriched PPI networks have been determined with the default parameter settings. PPI spider employs statistical methodology in which the $p$-value is adjusted for multiple testing (Bonferroni correction). The statistical significance of the inferred model is estimated based on the distribution of the model size for a random protein list. Statistical significance of the model is computed by a Monte Carlo simulation procedure $[37,38]$. Cytoscape software (http://www.cytoscape.org) was used for visualizing the obtained molecular interaction networks [39].

\section{Results}

\subsection{Cytotoxic effects of Aubipyc}

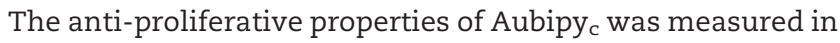
A2780/S cell line and compared with that of cisplatin as reported in the Materials and methods section. The $\mathrm{IC}_{50}$ values, observed after exposure to both Aubipy $y_{c}$ and cisplatin, are reported in Table 1 . After $24 \mathrm{~h}$ of exposure to Aubipyc, $\mathrm{IC}_{50}$ value was $10.73 \mu \mathrm{M}$ whereas that of cisplatin was about three-times higher (i.e. $34.15 \mu \mathrm{M}$ ). After $72 \mathrm{~h}$ of exposure to Aubipy $_{c}$ substantial cytotoxic activity was observed. IC 50 value of Aubipy $y_{c}$ fell in the low $\mu \mathrm{M}$ range and it was similar to $\mathrm{IC}_{50}$ obtained for cisplatin. These IC $_{50}$ values closely matched those recently determined on 36 different human tumor cell lines in Oncotest [40]. Aubipyc turned out to be less potent than other gold compounds such as Auoxo6 and Au2phen. In fact, Aubipyc was only moderately effective in the Oncotest panel but it was qualified as one of the most active gold(III) complexes on the A2780 line. Remarkably, this compound is able to overcome resistance to cisplatin [21].

\subsection{Proteomic results and statistical analysis}

To investigate the cytotoxic mechanism of Aubipyc, the protein expression modifications induced by gold treatment in A2780/S cells were analyzed with respect to untreated cells by 2-DE based proteomics. A2780/S cells were treated, for $24 \mathrm{~h}$, with Aubipy $\mathrm{c}_{\mathrm{c}}$ at a concentration corresponding to its 72-h-exposure IC $_{50}$ dose $(3.1 \mu \mathrm{M})$ in order to reduce the cell death and render a proteomic study well feasible. Indeed, a time course at 24,48 and $72 \mathrm{~h}$ drug exposures with $3.1 \mu \mathrm{M}$ of Aubipy $_{c}$, by using trypan blue vital dye exclusion assay, showed that after $24 \mathrm{~h}$ of exposure, the percentage of cell growth inhibition compared to the control was $13.4 \%$ and the viability of the adherent cells was $86.0 \%$. After $48 \mathrm{~h}$ and $72 \mathrm{~h}$ of drug exposure, the cell growth inhibition was 34.5 and $49.3 \%$, respectively, and the viability of the adherent cells was 86.5 and $85.8 \%$, respectively (Supplementary Table S1). After Aubipy treatment, cellular protein extracts were prepared and separated by 2-D gel electrophoresis as reported in the 'Material and methods' section and the resulting 2-DE gels were colloidal Coomassie blue silver-stained. To obtain statistically significant results, we performed three indepen-

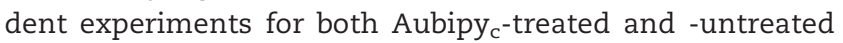
cells. To minimize gel-to-gel variation, 2-DE was performed twice for each biological replicate so that, 6 gels were analyzed for both Aubipyc-treated and control cells. In Fig. 2 representative 2-DE gels of control (A) and Aubipy -treated $^{-}$ A2780/S cells (B) are shown. The 2-DE gel images were analyzed by Progenesis SameSpots software 4.0 (Nonlinear Dynamics, UK) using default parameters. After automatic spot detection an average of about 1800 protein spots was detected in each gel. The computational 2-DE gel image

Table 1-Antiproliferative activity of Aubipyc and cisplatin against A2780/S ovarian carcinoma human cell line, sensitive to cisplatin.

\begin{tabular}{lll} 
& \multicolumn{2}{c}{$\mathrm{A} 2780 / \mathrm{S} \mathrm{IC}_{50}(\mu \mathrm{M}) \pm \mathrm{ES}$} \\
\cline { 2 - 3 } & \multicolumn{1}{c}{$24 \mathrm{~h}$} & \multicolumn{1}{c}{$72 \mathrm{~h}$} \\
\hline Aubipyc & $10.73 \pm 1.22$ & $3.10 \pm 0.10$ \\
$\mathrm{n}$ & 3 & 3 \\
Cisplatin & $34.15 \pm 0.17$ & $2.17 \pm 0.23$ \\
$\mathrm{n}$ & 3 & 3 \\
\hline
\end{tabular}

n, number of experiments; ES, standard error. 

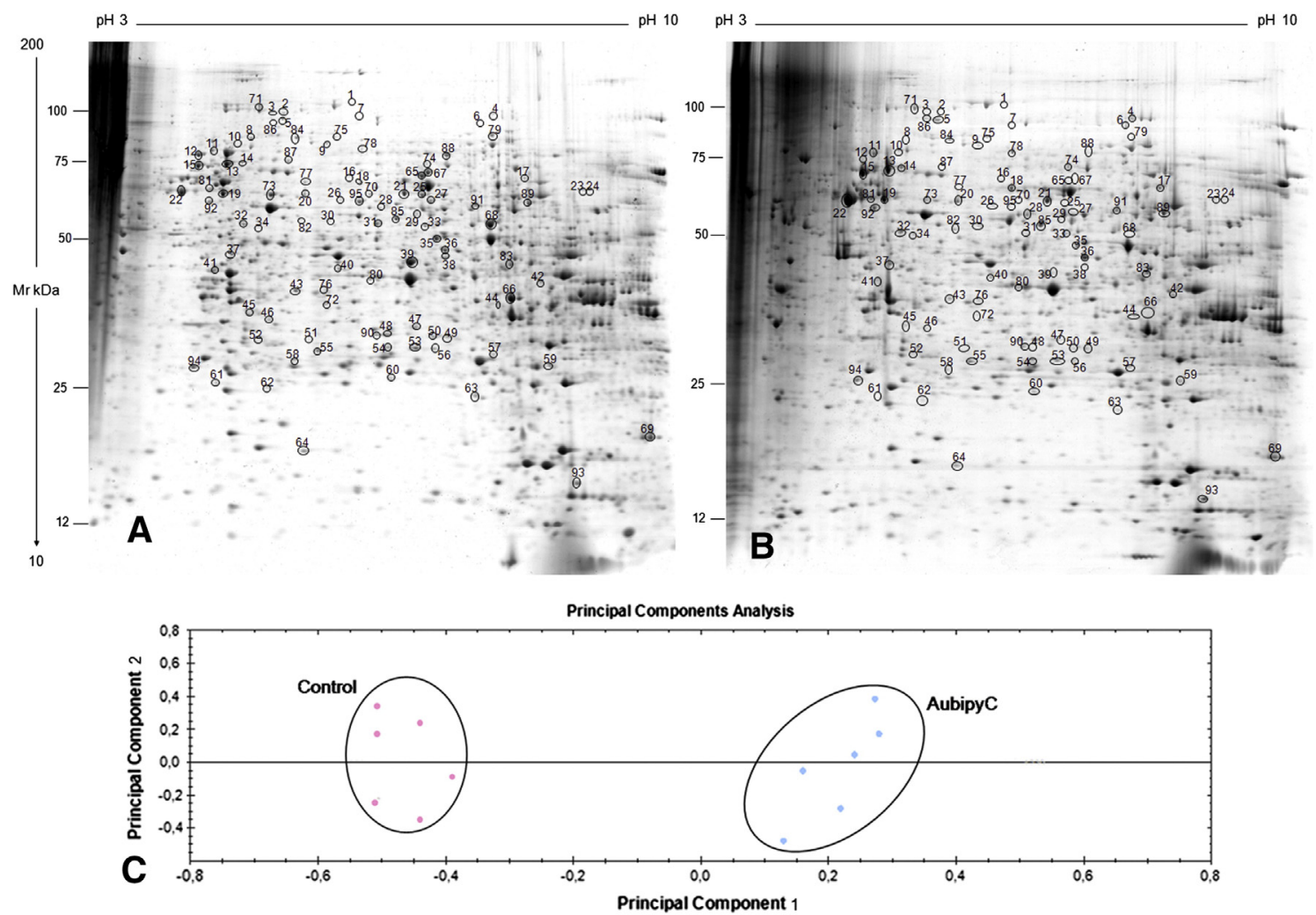

Fig. 2 - Representative colloidal Coomassie blue silver-stained 2-DE gel images for A2780/S control cells (A) and for Aubipyc-treated A2780/S cells (B). Whole-cellular proteins (700 $\mu \mathrm{g})$ were separated on IPG strips with a pH gradient of 3-10 nonlinear, followed by separation on 9-16\% linear gradient SDS-PAGE. Black circles and numbers indicate spots that were

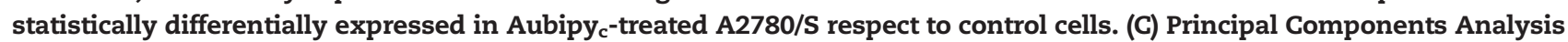
(PCA) performed by Progenesis SameSpots 4.0 software (Nonlinear Dynamic, UK).

analysis pointed out 102 differentially expressed protein spots (ANOVA $p$-value $\leq 0.05$ ). In addition to univariate analysis (ANOVA-test), multivariate analyses ( $q$-value, PCA and power analysis) were performed to explore categories of differential protein expression. To reduce the expected level of false positive we performed a statistical analysis on the ANOVA $p$-values, by applying the false discovery rate correction method known as $q$-value [41]. A statistically significant $q$-value $(\leq 0.05)$ was found for 95 protein spots. To obtain an overview of the

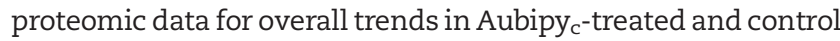
cells a multivariate analysis by PCA was performed. Gels were grouped according to the variance of their protein spot expression. The PCA biplot, shown in Fig. 2C, reveals two distinct expression profile groups corresponding to: i) Aubipy $_{c}$-treated A2780/S cells and ii) control cells. In the PCA plot each point describes the collective expression profiles of one sample and plot demonstrates consistent reproducibility between the six replicate samples within each group (treated and untreated cells). Moreover, we calculated the power of our statistical anal; [42]. In our experiments, we achieved a target power of $87 \%$ confirming that the number of sample replicates used was appropriate. We considered as statistically differentially expressed the protein spots with a $q$-value $\leq 0.05$ and a power $\geq 0.8$. Among the 95 differentially expressed protein spots, 35 factors were up-regulated where-

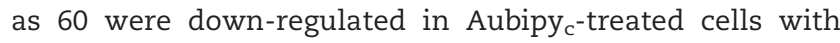

respect to control cells. Such protein spots are highlighted with circles and numbers in the representative gels shown in Fig. 2A and B. These spots were subjected to mass spectrometry analysis and 87 proteins were successfully identified: 29 up-regulated and 58 down-regulated after Aubipyc-treatment. The results of mass spectrometry identification are reported in Table 2, together with the corresponding spot numbers, score and coverage values of MALDI-TOF analysis, fold change in expression level and $q$-value. The experimental isoelectric point (pI) and molecular mass (Mr) values of the identified proteins mostly matched with those theoretically predicted from the genome sequence. More than one protein spot was found to correspond to the same protein, consistently with the presence of different post-translationally modified forms of the same proteins (Table 2). For example, we identified three spots as GAPDH, one of which (spot 66) was of higher molecular mass $(36 \mathrm{kDa})$ and two of which (spots 44 and 59) were of lower molecular mass ( $35 \mathrm{kDa}$ and $24 \mathrm{kDa}$ respectively). This may be tentatively explained with the presence of post-translationally modified forms of GAPDH in agreement with several 2-DEbased studies which report the identification of this protein in spots with different position on 2-D gels $[43,44]$. In some instances, the same protein was identified in spots that displayed a strong discrepancy between the observed position on 2-DE gels and the normal Mr, with a shift toward lower mass (e.g. spots $33,35,38,53$ ) suggesting the presence of protein 
fragmentation (Table 2, Fig. 2). Moreover, it is of particular interest that differentially expressed protein spots were found to be products of the same gene. In particular, for some spots, in Aubipy $_{\mathrm{c}}$ treated cells, we observed a decrease of the full length protein amount with a concomitant increase of protein forms with lower Mr, suggesting the presence of protein fragments. For example, in treated cells, we identified four spots as HSP704L, of which two of higher molecular mass (about $94 \mathrm{kDa}$, matching with the predicted $\mathrm{Mr}$ ) were decreased, whereas two of lower molecular mass (about $88 \mathrm{kDa}$ ) were increased. Hsc71, T-complex protein 1 subunit alpha and GMPS showed the same trend (Table 2, Fig. 2).

The final number of unique identified proteins was 26 for the up-regulated proteins and 45 for those down-regulated. All the identified proteins were classified into functional categories on the basis of the Gene Ontology (GO) terms related to their major biological functions using UniprotKB database (http://www.uniprot.org/). In Fig. 3 we reported the percentage of both up-regulated and down-regulated proteins, annotated in each functional category. Most of the up-regulated proteins belong to the functional classes of stress response and chaperones (41.5\%), protein synthesis (17.2\%), metabolism (13.8\%) and cytoskeleton and cell structure (13.8\%). The remaining identified proteins are shared out among cell cycle and apoptosis (3.4\%), cell redox homeostasis (3.4\%) and DNA replication and repair (6.9\%). Concerning the down-regulated proteins, the most represented classes were those of metabolism (31\%), protein synthesis (22.4\%), stress response and chaperones (19\%) and cell redox homeostasis (10.3\%). The smaller functional classes are transport (7\%), cell cycle and apoptosis (5.2\%), signal transduction (3.4\%) and cytoskeleton and cell structure (1.7\%).

\subsection{Functional GO terms and pathway enrichment analysis}

To better understand biological meaning behind the list of proteins obtained after the Aubipyc treatment we used the web-accessible program DAVID (Database Annotation Visualization and Integrated Discovery version $6.7 \mathrm{http} / / /$ david.abcc. ncifcrf.gov/home.jsp) $[45,46]$ and relative functional annotation tools. DAVID provides information whether any GO categories were statistically enriched by a gene/protein list. To this aim we uploaded two different lists containing the: i) up-regulated protein and ii) down-regulated protein, respectively. A Fisher's enrichment analysis was carried out by comparing the frequencies of the annotation terms in each protein subset with that of the whole list. Fig. 4 displays the obtained GO Biological Process (BP) terms statistically over-represented ( $p$-value $\leq 0.1$ after Benjamini correction). Detailed composition and statistical parameters were reported in Table S2. Most of the top score biological processes, enriched by the 29 up-regulated proteins (Fig. 4A), included ontologies involved in protein synthesis and folding: 'protein folding' (GO:0006457), 'protein metabolic process' (GO:0019538) and 'cellular protein metabolic process'(GO:0044267). In these GO BP terms we found the proteins corresponding to the functional category 'stress response and chaperones' reported in Table 2. We found different subunits of T-complex protein 1 . The TCP-1 chaperonin family known as 'eukaryotic cytosolic chaperonin containing TCP-1 (CCT)' has a critical function in the folding of many proteins, including the cytoskeletal components actin and tubulin [47]. We also found different members of the heat shock family such as, HSP60 mitochondrial, Hsc71 and Heat shock $70 \mathrm{kDa}$ protein $4 \mathrm{~L}$. Concerning the enriched GO terms associated with protein metabolism we found two elongation factors such as Elongation factor $\mathrm{Tu}$ mitochondrial and Elongation factor 2, the protein pre-mRNA-processing factor 19 involved in spliceosome assembly, the RuvB-like 1 important for DNA repair and the dihydrolipoyl dehydrogenase mitochondrial associated with protein folding. Several proteins are shared between different GO terms all related to cellular metabolism (GO:0009987, GO:0044237, GO:0044238, GO:0008152). These terms contained all the proteins found in the enriched BP terms described above together with the mitochondrial $\mathrm{NADH}$-ubiquinone oxidoreductase $75 \mathrm{kDa}$ subunit involved in cellular respiration and two proteins involved in purine metabolism such as c-1-tetrahydrofolate synthase and GMP synthetase. Proteins involved in mRNA processing such as heterogeneous nuclear ribonucleoprotein $\mathrm{H}$, heterogeneous nuclear ribonucleoprotein $\mathrm{K}$ and heterogeneous nuclear ribonucleoprotein $\mathrm{Q}$ are also included. Three up-regulated proteins are involved in cytoskeleton rearrangement such as ezrin, vinculin and actin-related protein 3. This finding is in agreement with the data on the TCP-1 chaperonin family that acts primary on cytoskeleton remodeling.

The top score GO BP terms enriched by the down-regulated protein list (Fig. 4B and Table S2) included ontologies associated with metabolism and energy production such as 'metabolic process' (GO:0008152), 'cellular metabolic process' (GO:0044237), 'generation of precursor metabolites and energy' (GO:0006091) and 'glycolysis' (GO:0006096). Several isoforms of glycolytic enzymes such as glyceraldehyde-3-phosphate dehydrogenase (GAPDH), alpha enolase (ENO1), phosphoglycerate kinase 1 (PGK1) and pyruvate kinase isozymes M1/M2 (PKM) were included in these categories. Also, mitochondrial proteins involved in energy production (ATP synthase subunit alpha, enoyl-CoA hydratase, and ketoacid coenzyme A transferase 1) were present. Interestingly, we found enriched the BP term 'cell redox homeostasis' (GO:0045454, including mitochondrial SCO2 homolog peroxiredoxin- 6 protein disulfide-isomerase A3 and the cytoplasmic thioredoxin reductase 1), suggesting a drug-induced reduction of antioxidant potential of the cells. In parallel to this GO enrichment analysis, we also searched for statistically enriched pathways through DAVID software. Using the list of the down-regulated proteins, we found over-represented the 'glycolysis pathway' with both Biocarta and KEGG pathways ( $p$-value $<0.1$ after Benjamini correction). This pathway enrichment confirmed the GO BP term observations achieved with the down-regulated proteins, where the term 'glycolysis' were over-represented (Fig. 4B and Table S2). The proteins associated with the term 'glycolysis', are GAPDH, PGK1, ENO1 and PKM (Fig. 5).

\subsection{Protein validation by Western blot}

Western blot analysis was used to validate the expression changes of the glycolytic enzymes GAPDH, PGK1, ENO1 and $\mathrm{PKM}$ in $\mathrm{A} 2780 / \mathrm{S}$ treated for $24 \mathrm{~h}$ with $3.1 \mu \mathrm{M}$ Aubipy $_{\mathrm{c}}$. A representative immunoblot was shown in Fig. $6 \mathrm{~A}$ whereas the complete blot is provided in Fig. S1. For each tested protein the 
Table 2 - Differentially expressed protein spots identified by MALDI TOF mass spectrometry analysis.

\begin{tabular}{|c|c|c|c|c|c|c|c|c|c|c|}
\hline \multirow{2}{*}{$\begin{array}{l}\text { Spot } \\
\text { no. }{ }^{a}\end{array}$} & \multirow[t]{2}{*}{ Protein description } & \multirow[t]{2}{*}{$\mathrm{AC}^{\mathrm{b}}$} & \multirow{2}{*}{$\begin{array}{l}\text { Gene } \\
\text { name }\end{array}$} & \multirow{2}{*}{$\begin{array}{l}\text { Subcellular } \\
\text { localization }\end{array}$} & \multicolumn{3}{|c|}{ Mascot search results } & \multirow{2}{*}{$\begin{array}{c}\text { Fold change } \\
\text { (Aubipyc us } \\
\text { Control) }\end{array}$} & \multirow{2}{*}{$\begin{array}{l}\text { ANOVA } \\
p \text {-value }\end{array}$} & \multirow[t]{2}{*}{$q$-value ${ }^{h}$} \\
\hline & & & & & Score $^{c}$ & $\begin{array}{l}\text { Matched } \\
\text { Pept. }^{d}\end{array}$ & $\begin{array}{l}\text { Seq. } \\
\text { coverage } \\
(\%)^{\mathrm{e}}\end{array}$ & & & \\
\hline \multicolumn{11}{|c|}{ Stress response and chaperones } \\
\hline 2 & Heat shock 70 kDa protein 4L & 095757 & HSPA4L & Cytosol & 220 & $23 / 33$ & 30 & -1.6 & 0.038 & $<0.05$ \\
\hline 3 & Heat shock 70 kDa protein 4L & 095757 & HSPA4L & Cytosol & 160 & $18 / 32$ & 30 & -1.8 & 0.002 & $<0.02$ \\
\hline 5 & Heat shock 70 kDa protein 4L & 095757 & HSPA4L & Cytosol & 382 & $42 / 56$ & 54 & 2 & 0.036 & $<0.05$ \\
\hline 86 & Heat shock $70 \mathrm{kDa}$ protein $4 \mathrm{~L}$ & 095757 & HSPA4L & Cytosol & 206 & $21 / 29$ & 28 & 1.8 & 0.029 & $<0.05$ \\
\hline 13 & Stress-70 protein, mitochondrial & P38646 & HSPA9 & mitochondrion & 376 & $50 / 86$ & 63 & 1.9 & 0.029 & $<0.05$ \\
\hline 14 & Stress-70 protein, mitochondria & P38646 & HSPA9 & Mitochondrion & 324 & $34 / 52$ & 54 & 1.7 & 0.021 & $<0.05$ \\
\hline 12 & Heat shock cognate $71 \mathrm{kDa}$ protein & P11142 & HSPA8 & Cytosol & 241 & $31 / 69$ & 55 & -2.9 & 0.003 & $<0.02$ \\
\hline 15 & Heat shock cognate $71 \mathrm{kDa}$ protein & P11142 & HSPA8 & Cytosol & 233 & $32 / 71$ & 56 & 2.2 & 0.033 & $<0.05$ \\
\hline 56 & $\begin{array}{l}\text { Heat shock cognate } 71 \mathrm{kDa} \text { protein } \\
\text { (N-fragment) }\end{array}$ & P11142 & HSPA8 & Cytosol & 159 & $22 / 46$ & 30 & -2 & 0.018 & $<0.05$ \\
\hline 18 & T-complex protein 1 subunit gamma & P49368 & ССТ3 & Cytosol & 208 & $22 / 31$ & 39 & 1.6 & 0.029 & $<0.05$ \\
\hline 19 & T-complex protein 1 subunit epsilon & P48643 & ССT5 & Cytosol & 325 & $49 / 83$ & 75 & 1.3 & 0.0001 & $<0.005$ \\
\hline 81 & T-complex protein 1 subunit epsilon & P48643 & ССТ5 & Cytosol & 250 & $39 / 81$ & 70 & 1.8 & 0.014 & $<0.04$ \\
\hline 20 & T-complex protein 1 subunit alpha & P17987 & TCP1 & Cytosol & 188 & $20 / 35$ & 47 & 1.8 & 0.006 & $<0.03$ \\
\hline 77 & T-complex protein 1 subunit alpha & P17987 & TCP1 & Cytosol & 268 & $25 / 40$ & 54 & -2.4 & 0.005 & $<0.03$ \\
\hline 21 & T-complex protein 1 subunit zeta & P40227 & ССТ6А & Cytosol & 155 & $27 / 93$ & 48 & 1.7 & 0.034 & $<0.05$ \\
\hline 38 & T-complex protein 1 subunit beta & P78371 & ССТ2 & Cytosol & 152 & $17 / 34$ & 35 & -2 & 0.028 & $<0.05$ \\
\hline 95 & T-complex protein 1 subunit beta & P78371 & ССТ2 & Cytosol & 350 & $43 / 89$ & 81 & -2.2 & 0.031 & $<0.05$ \\
\hline 89 & T-complex protein 1 subunit eta & Q99832 & CCT7 & Cytosol & 271 & $36 / 75$ & 67 & 1.6 & 0.032 & $<0.05$ \\
\hline 60 & LDLR chaperone MESD & Q14696 & MESDC2 & $\begin{array}{l}\text { Endoplasm } \\
\text { reticulum }\end{array}$ & 74 & $7 / 21$ & 32 & -1.5 & 0.029 & $<0.05$ \\
\hline 22 & $60 \mathrm{kDa}$ heat shock protein, mitochondrial & P10809 & HSPD1 & Mitochondrion & 170 & $23 / 49$ & 51 & 2 & 0.007 & $<0.04$ \\
\hline 35 & Stress-induced-phosphoprotein 1 & P31948 & STIP1 & Cytosol/nucleus & 177 & $32 / 86$ & 51 & -1.9 & 0.033 & $<0.05$ \\
\hline 67 & Stress-induced-phosphoprotein 1 & P31948 & STIP1 & Cytosol/nucleus & 129 & $13 / 21$ & 27 & -7.6 & 0.0005 & $<0.01$ \\
\hline 69 & Peptidyl-prolyl cis-trans isomerase B & P23284 & PPIB & Endoplasm. reticulum & 154 & $21 / 68$ & 51 & -1.4 & 0.0005 & $<0.01$ \\
\hline \multicolumn{11}{|c|}{ Metabolism } \\
\hline \multicolumn{11}{|c|}{ Glucose metabolism } \\
\hline 43 & $\begin{array}{l}\text { Pyruvate kinase isozymes M1/M2 } \\
\text { (N-fragment) }\end{array}$ & P14618 & PKM & Cytosol & 309 & $30 / 46$ & 46 & -2 & 0.021 & $<0.05$ \\
\hline 58 & $\begin{array}{l}\text { Pyruvate kinase isozymes M1/M2 } \\
\text { (N-fragment) }\end{array}$ & P14618 & PKM & Cytosol & 116 & $13 / 31$ & 31 & -2.3 & 0.027 & $<0.05$ \\
\hline 80 & Pyruvate kinase isozymes M1/M2 & P14618 & PKM & Cytosol & 130 & $23 / 95$ & 43 & -2.4 & 0.008 & $<0.05$ \\
\hline 44 & Glyceraldehyde-3-phosphate dehydrogenase & P04406 & GAPDH & Cytosol & 91 & $13 / 54$ & 33 & -1.6 & 0.028 & $<0.05$ \\
\hline 59 & Glyceraldehyde-3-phosphate dehydrogenase & P04406 & GAPDH & Cytosol & 86 & $13 / 51$ & 41 & -1.7 & 0.038 & $<0.05$ \\
\hline 66 & Glyceraldehyde-3-phosphate dehydrogenase & P04406 & GAPDH & Cytosol & 157 & $27 / 87$ & 68 & -6.2 & 0.005 & $<0.03$ \\
\hline 68 & Alpha-enolase & P06733 & ENO1 & Cytosol & 289 & $31 / 62$ & 70 & -2.3 & 0.0002 & $<0.005$ \\
\hline 83 & Phosphoglycerate kinase 1 & P00558 & PGK1 & Cytosol & 100 & $15 / 59$ & 42 & -1.5 & 0.024 & $<0.05$ \\
\hline \multicolumn{11}{|c|}{ Galactose metabolism } \\
\hline 40 & Galactokinase & P51570 & GALK1 & Cytosol & 338 & 29/61 & 71 & -1.7 & 0.037 & $<0.05$ \\
\hline
\end{tabular}




\begin{tabular}{|c|c|c|c|c|c|c|c|c|c|c|}
\hline \multicolumn{11}{|c|}{ Retinol metabolism } \\
\hline 29 & Retinal dehydrogenase 1 & P00352 & ALDH1A1 & Cytosol & 131 & $17 / 55$ & 41 & -1.5 & 0.038 & $<0.05$ \\
\hline \multicolumn{11}{|c|}{ Cellular respiration and ATP metabolism } \\
\hline 11 & $\begin{array}{l}\text { NADH-ubiquinone oxidoreductase } 75 \mathrm{kDa} \text { subunit, } \\
\text { mitochondrial }\end{array}$ & P28331 & NDUFS1 & Mitochondrion & 362 & $51 / 90$ & 59 & 1.7 & 0.035 & $<0.05$ \\
\hline 63 & ATP synthase subunit alpha, mitochondrial & P25705 & ATP5A1 & Mitochondrion & 158 & $22 / 48$ & 36 & -3.6 & 0.025 & $<0.05$ \\
\hline 91 & Dihydrolipoyl dehydrogenase, mitochondrial & P09622 & DLD & Mitochondrion & 167 & $21 / 47$ & 45 & 1.5 & 0.040 & $<0.05$ \\
\hline \multicolumn{11}{|c|}{ Lipid metabolism } \\
\hline 47 & Isocitrate dehydrogenase & O75874 & IDH1 & Cytosol/peroxis & 172 & $20 / 55$ & 48 & -2.5 & 0.039 & $<0.05$ \\
\hline 55 & Enoyl-CoA hydratase, mitochondrial & P30084 & ECHS1 & Mitochondrion & 160 & $22 / 65$ & 50 & -1.8 & 0.036 & $<0.05$ \\
\hline \multicolumn{11}{|c|}{ Ketone metabolism } \\
\hline 70 & $\begin{array}{l}\text { Succinyl-CoA: 3-ketoacid coenzyme A transferase } \\
\text { 1, mitochondrial }\end{array}$ & P55809 & OXCT1 & Mitochondrion & 154 & $17 / 36$ & 45 & -5.9 & 0.00007 & $<0.01$ \\
\hline \multicolumn{11}{|c|}{ Amino-acid and protein metabolism } \\
\hline 25 & D-3-phosphoglycerate dehydrogenase & 043175 & PHGDH & Cytosol & 192 & $24 / 59$ & 43 & -3.9 & 0.037 & $<0.05$ \\
\hline 27 & Cytosol aminopeptidase & P28838 & LAP3 & Cytosol & 169 & $21 / 63$ & 50 & -4.4 & 0.013 & $<0.04$ \\
\hline \multicolumn{11}{|c|}{ Purine metabolism } \\
\hline 65 & Bifunctional purine biosynthesis protein PURH & P31939 & ATIC & Mitochondrion & 379 & $40 / 78$ & 73 & -2.6 & 0.0003 & $<0.01$ \\
\hline 4 & C-1-tetrahydrofolate synthase, cytoplasmic & P11586 & MTHFD1 & Cytosol & 127 & $21 / 60$ & 23 & 2.3 & 0.011 & $<0.04$ \\
\hline 88 & GMP synthase [glutamine-hydrolyzing] & P49915 & GMPS & Cytosol & 340 & $39 / 77$ & 57 & -1.6 & 0.030 & $<0.05$ \\
\hline 74 & GMP synthase [glutamine-hydrolyzing] & P49915 & GMPS & Cytosol & 338 & $29 / 35$ & 48 & 1.8 & 0.002 & $<0.02$ \\
\hline \multicolumn{11}{|c|}{ Transport } \\
\hline 9 & Mitochondrial inner membrane protein & Q16891 & IMMT & Mitochondrion & 178 & $17 / 25$ & 27 & -1.4 & 0.035 & $<0.05$ \\
\hline 84 & Mitochondrial inner membrane protein & Q16891 & IMMT & Mitochondrion & 250 & $36 / 90$ & 42 & -1.5 & 0.003 & $<0.02$ \\
\hline 57 & Protein SCO2 homolog, mitochondrial & 043819 & SCO2 & Mitochondrion & 105 & $12 / 69$ & 55 & -1.7 & 0.032 & $<0.05$ \\
\hline 49 & Voltage-dependent anion-selective channel protein 2 & P45880 & VDAC2 & Mitochondrion & 110 & $13 / 73$ & 64 & -1.4 & 0.020 & $<0.05$ \\
\hline \multicolumn{11}{|c|}{ Protein synthesis } \\
\hline 6 & Elongation factor 2 & P13639 & EEF2 & Cytosol & 331 & $35 / 47$ & 49 & 2.9 & 0.034 & $<0.05$ \\
\hline 33 & Elongation factor 2 & P13639 & EEF2 & Cytosol & 218 & $32 / 67$ & 40 & -2 & 0.030 & $<0.05$ \\
\hline 53 & Elongation factor 2 & P13639 & EEF2 & Cytosol & 107 & $22 / 67$ & 25 & -2.3 & 0.010 & $<0.04$ \\
\hline 36 & Elongation factor $\mathrm{Tu}$, mitochondrial & P49411 & TUFM & Mitochondrion & 224 & $27 / 79$ & 65 & 1.6 & 0.022 & $<0.05$ \\
\hline 16 & Cleavage stimulation factor subunit 2 & P33240 & CSTF2 & Nucleus & 170 & $16 / 21$ & 31 & -1.4 & 0.039 & $<0.05$ \\
\hline 79 & Far upstream element-binding protein 2 & Q92945 & KHSRP & Nucleus & 250 & $23 / 38$ & 40 & -2.8 & 0.008 & $<0.04$ \\
\hline 23 & Far upstream element-binding protein 3 & Q96I24 & FUBP3 & Nucleus & 208 & $18 / 33$ & 49 & -1.8 & 0.037 & $<0.05$ \\
\hline 24 & Far upstream element-binding protein 3 & Q96124 & FUBP3 & Nucleus & 282 & $27 / 38$ & 53 & -1.6 & 0.039 & $<0.05$ \\
\hline 28 & Pre-mRNA-processing factor 19 & Q9UMS4 & PRPF19 & Nucleus & 106 & $15 / 53$ & 37 & 1.7 & 0.017 & $<0.05$ \\
\hline 30 & Mitochondrial-processing peptidase subunit alpha & Q10713 & PMPCA & Mitochondrion & 93 & $16 / 69$ & 33 & -1.4 & 0.038 & $<0.05$ \\
\hline 45 & Serine/arginine-rich splicing factor 1 & Q07955 & SRSF1 & Nucleus & 123 & $13 / 47$ & 47 & -2.3 & 0.036 & $<0.05$ \\
\hline 42 & Heterogeneous nuclear ribonucleoprotein $\mathrm{A} / \mathrm{B}$ & Q99729 & HNRNPAB & Nucleus & 134 & $15 / 38$ & 31 & -2.1 & 0.026 & $<0.05$ \\
\hline 17 & Heterogeneous nuclear ribonucleoprotein Q & 060506 & SYNCRIP & Nucleus & 282 & $26 / 41$ & 43 & 2.2 & 0.0007 & $<0.01$ \\
\hline 92 & Heterogeneous nuclear ribonucleoprotein $\mathrm{K}$ & P61978 & HNRNPKH & Nucleus & 118 & $16 / 54$ & 42 & 1.8 & 0.040 & $<0.05$ \\
\hline 62 & $\begin{array}{l}\text { Heterogeneous nuclear ribonucleoprotein } \mathrm{H} \\
\text { (N-fragment) }\end{array}$ & P31943 & HNRNPH1 & Nucleus & 110 & $15 / 46$ & 36 & -1.9 & 0.023 & $<0.05$ \\
\hline
\end{tabular}




\begin{tabular}{|c|c|c|c|c|c|c|c|c|c|c|}
\hline \multirow{2}{*}{$\begin{array}{l}\text { Spot } \\
\text { no. }{ }^{a}\end{array}$} & \multirow[t]{2}{*}{ Protein description } & \multirow[t]{2}{*}{$\mathrm{AC}^{\mathrm{b}}$} & \multirow{2}{*}{$\begin{array}{l}\text { Gene } \\
\text { name }\end{array}$} & \multirow{2}{*}{$\begin{array}{l}\text { Subcellular } \\
\text { localization }\end{array}$} & \multicolumn{3}{|c|}{ Mascot search results } & \multirow{2}{*}{$\begin{array}{c}\text { Fold change } \\
\text { (Aubipyc us } \\
\text { Control) }\end{array}$} & \multirow{2}{*}{$\begin{array}{l}\text { ANOVA } \\
p \text {-value }\end{array}$} & \multirow[t]{2}{*}{$q$-value ${ }^{h}$} \\
\hline & & & & & Score $^{c}$ & $\begin{array}{l}\text { Matched } \\
\text { Pept. }\end{array}$ & $\begin{array}{c}\text { Seq. } \\
\text { coverage } \\
(\%)^{\mathrm{e}}\end{array}$ & & & \\
\hline 82 & Heterogeneous nuclear ribonucleoprotein $\mathrm{H}$ & P31943 & HNRNPH1 & Nucleus & 160 & $17 / 36$ & 42 & 2.1 & 0.022 & $<0.05$ \\
\hline 64 & Calreticulin (N-fragment) & P27797 & CALR & Endo. reticulum & 82 & $8 / 21$ & 15 & -1.7 & 0.020 & $<0.05$ \\
\hline 90 & Eukaryotic translation initiation factor $4 \mathrm{H}$ & Q15056 & EIF4H & Cytosol & 147 & $17 / 54$ & 57 & -1.9 & 0.034 & $<0.05$ \\
\hline \multicolumn{11}{|c|}{ Cell cycle and apoptosis } \\
\hline 7 & Programmed cell death 6-interacting protein & Q8WUM4 & PDCD6IP & Cytosol & 208 & $17 / 18$ & 17 & 2.3 & 0.031 & $<0.05$ \\
\hline 41 & Anamorsin & Q6FI81 & CIAPIN1 & Cytosol/nucleus & 169 & $18 / 72$ & 61 & -1.7 & 0.035 & $<0.05$ \\
\hline 31 & Proliferation-associated protein 2G4 & Q9UQ80 & PA2G4 & Cytosol/nucleus & 182 & $26 / 54$ & 54 & -2.7 & 0.010 & $<0.04$ \\
\hline 52 & Prohibitin & P35232 & PHB & Mitochondrion & 58 & $8 / 64$ & 39 & -2 & 0.023 & $<0.05$ \\
\hline \multicolumn{11}{|c|}{ Cell redox homeostasis } \\
\hline 26 & Thioredoxin reductase 1 , cytoplasmic & Q16881 & TXNRD1 & Cytosol & 62 & $12 / 65$ & 27 & -1.2 & 0.040 & $<0.05$ \\
\hline 32 & Glutathione synthetase & P48637 & GSS & Cytosol & 212 & $24 / 61$ & 54 & 1.4 & 0.028 & $<0.05$ \\
\hline 48 & Peroxiredoxin- 6 & P30041 & PRDX6 & Cytosol & 248 & $22 / 67$ & 83 & -4.6 & 0.040 & $<0.05$ \\
\hline 54 & Peroxiredoxin- 6 & P30041 & PRDX6 & Cytosol & 103 & $10 / 46$ & 52 & -1.7 & 0.040 & $<0.05$ \\
\hline 76 & 3-mercaptopyruvate sulfurtransferase & P25325 & MPST & Mitochondrion & 167 & 20/81 & 69 & -1.6 & 0.002 & $<0.02$ \\
\hline 50 & Protein disulfide-isomerase A3 (C-fragment) & P30101 & PDIA3 & Endoplasm. reticulum & 105 & $18 / 63$ & 31 & -2.8 & 0.025 & $<0.05$ \\
\hline 73 & Protein disulfide-isomerase $\mathrm{A} 3$ & P30101 & PDIA3 & Endoplasm. reticulum & 182 & $26 / 90$ & 48 & -1.6 & 0.018 & $<0.05$ \\
\hline \multicolumn{11}{|c|}{ Signal transduction } \\
\hline 61 & Heme-binding protein 1 & Q9NRV9 & HEBP1 & Mitochondrion & 200 & $21 / 55$ & 90 & -2.2 & 0.008 & $<0.04$ \\
\hline 51 & $\begin{array}{l}\text { Ankyrin repeat domain-containing } \\
\text { protein } 42\end{array}$ & Q8N9B4 & ANKRD42 & Nucleus & 62 & $7 / 28$ & 23 & -3.5 & 0.008 & $<0.04$ \\
\hline \multicolumn{11}{|c|}{ Cytoskeleton and cell structure } \\
\hline 1 & Vinculin & P18206 & VCL & Cytoskeleton & 283 & 29/37 & 32 & 1.8 & 0.006 & $<0.03$ \\
\hline 71 & Vinculin & P18206 & VCL & Cytoskeleton & 363 & $50 / 82$ & 45 & -3.9 & 0.0001 & $<0.005$ \\
\hline 34 & Actin-related protein 3 & P61158 & ACTR3 & Cytoskeleton & 219 & $25 / 64$ & 61 & 1.6 & 0.008 & $<0.04$ \\
\hline 75 & Protein enabled homolog & Q8N8S7 & ENAH & Cytoskeleton & 183 & $18 / 29$ & 28 & -2.7 & 0.002 & $<0.02$ \\
\hline 78 & Ezrin & P15311 & EZR & Cytoskeleton & 278 & $35 / 58$ & 49 & 2 & 0.008 & $<0.04$ \\
\hline \multicolumn{11}{|c|}{ DNA replication and repair } \\
\hline 85 & RuvB-like 1 & Q9Y265 & RUVBL1 & Nucleus & 269 & $30 / 63$ & 61 & 1.7 & 0.028 & $<0.05$ \\
\hline 93 & Single-stranded DNA-binding protein, mitochondrial & Q04837 & SSBP1 & Mitochondrion & 117 & $13 / 42$ & 62 & 1.2 & 0.040 & $<0.05$ \\
\hline
\end{tabular}

a Spot numbers match those reported in the representative 2-DE images shown in Fig. 2 (panels A and B).

${ }^{\mathrm{b}}$ Accession number in Swiss-Prot/UniprotKB.

${ }^{c}$ MASCOT MS score (Matrix Science, London, UK; http://www.matrixscience.com). MS matching score greater than 56 was required for a significant MS hit ( $p$-value $<0.05$ ).

d Number of matched peptides correspond to peptide masses matching the top hit from Ms-Fit PMF, searched peptide are also reported.

e Sequence coverage = (number of the identified residues / total number of amino acid residues in the protein sequence) $\times 100 \%$.

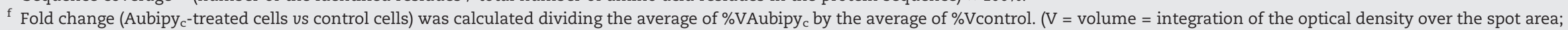
$\% \mathrm{~V}=\mathrm{V}$ single spot/V total spots included in the reference gel) using Progenesis SameSpots 4.0 software.

$\mathrm{g}$ Anova test was performed by Progenesis SameSpots 4.0 software to determine if the relative change was statistically significant $(p<0.05)$.

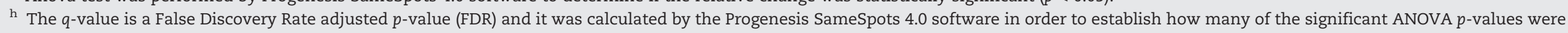
false positives. Only the protein spots with a $q$-value $<0.05$ were considered for the mass spectrometry analysis. 


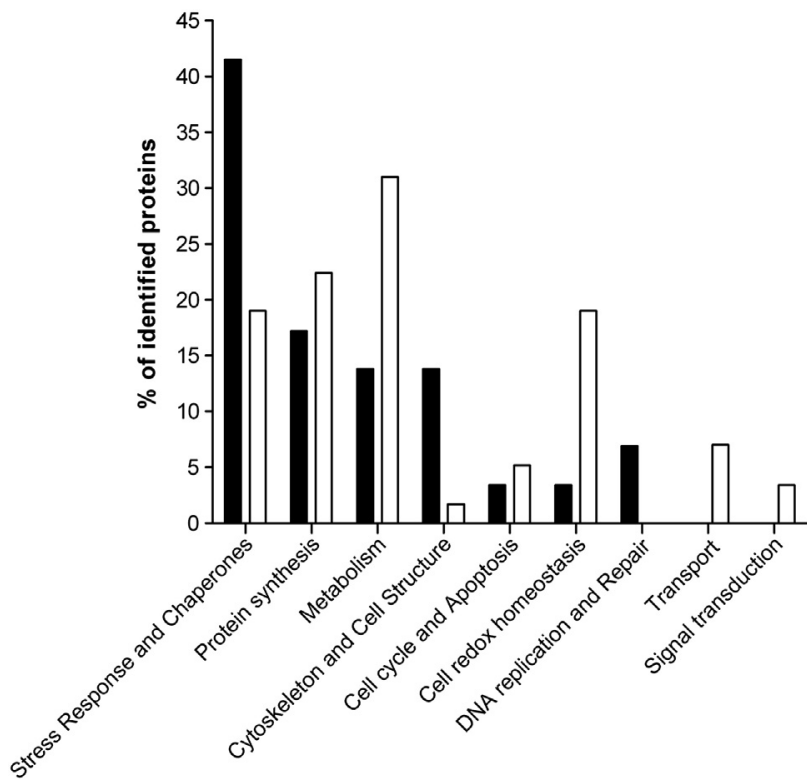

Fig. 3 - Functional classification of differentially expressed protein spots. The identified protein spots were sorted into functional categories on the basis of the Gene Ontology (GO) terms related to their major biological functions using UniprotKB database (http://www.uniprot.org/). In the histogram is reported the percentage of the up-regulated proteins (black bars) and down-regulated proteins (white bars) allocated in each functional category.

optical density of specific immunoreactive band was determined and the values were statistically analyzed by two-tailed non-paired Student-t-test. The resulting mean values $\pm S D$, of three independent experiments, were reported in the bar graph in Fig. 6B. We found that the amount of these glycolytic

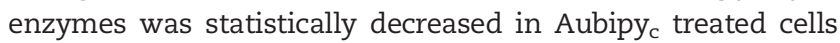
with respect to controls ( $p$-value $<0.05$ ). The overall results confirmed both the proteomic data and the pathway enrichment analysis. It must be said, however, that GAPDH and PKM Western blot results were not completely in line with those of 2-DE. In GAPDH blot, we detected only the band of $36 \mathrm{kDa}$ corresponding to full length protein (spot) whereas the bands of $35 \mathrm{kDa}$ (spot 44) and $24 \mathrm{kDa}$ (spot 59) were not detected by anti-GAPDH antibody. In PKM blot, we detected the band of $57 \mathrm{kDa}$ corresponding to full length protein (spot 80) and the band of $36 \mathrm{kDa}$ (spot 43) identified by mass spectrometry as fragment. The band of $24 \mathrm{kDa}$ (spot 43) was not revealed in this blot. This discrepancy, between proteomic data and Western blot, could be due to the lower amount of these undetected bands or to the lack in the protein fragments of epitopes recognized by antibodies. There is some solid evidence that gold based drugs mainly act through modification of selected proteins ('protein metalation') with consequent loss of function and destruction $[48,49]$. Therefore, to evaluate if, in our study, the decreased amount of these enzymes was due to an increased degradation, we performed the Western blot analysis on A2780 cells treated also for $48 \mathrm{~h}$. The results at this time were similar to that at $24 \mathrm{~h}$ (Fig. S1). Indeed, for all the validated enzymes, the amount of the relative full length protein was statistically lower in gold treated cells with respect to controls ( $p$-value $<0.05$ ) but we did not observe a concomitant appearance of protein fragments. Since the proteomics and the Western blots allow to detect only stable protein fragments, these results did not clarify whether the decrease in the amount of these proteins is due to increased degradation or decreased synthesis. Additional experiments are needed.

\subsection{Metabolic investigations}

Proteomic and bioinformatic results suggested a possible cytotoxic effect of Aubipyc, directly or indirectly, on glycolysis pathway. To investigate this hypothesis, we decided to perform two additional experiments: i) the measure of the decrease in glucose level in the culture medium and ii) the assessment of the effect of extra pyruvate addition in the culture medium on antiproliferative activity of Aubipy A $_{c}$ against A2780/S cells. Concerning the glucose assay, we cultured the treated and untreated A2780/S cells for $48 \mathrm{~h}$. Glucose concentration was measured in $1 \mathrm{~mL}$ of medium supernatant harvested immediately after the addition of $3.1 \mu \mathrm{M}$ Aubipy $_{\mathrm{c}}$ (time 0 ) and then after 6, 12, 24, and $48 \mathrm{~h}$. Experiments were performed in triplicate. The resulting mean values \pm SD were reported in the bar graph in Fig. 7. We found that at both 24 and $48 \mathrm{~h}$ the glucose level was

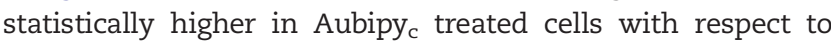
controls ( $p$-value $<0.05$ by two-tailed non-paired Student's-ttest). In treated cells we measured a glucose amount of 1.3 times higher at $24 \mathrm{~h}$ and 2 times higher at $48 \mathrm{~h}$ than in control cells. Thus, this result showed that Aubipy $y_{c}$ treated cells consume less glucose than controls. Concerning the addition of extra pyruvate in the culture medium, we observed that it induced an increase of the $\mathrm{IC}_{50}$ drug concentration value (Table 3). As reported in Section 3.1 and in Table 1, after $72 \mathrm{~h}$ of exposure to Aubipy $_{c}$, the IC $\mathrm{IC}_{50}$ value was $3.1 \mu \mathrm{M}$. In the presence of $1 \mathrm{mM}$ of pyruvate, the $\mathrm{IC}_{50}$ value turned out to be $8.4 \mu \mathrm{M}$ at $72 \mathrm{~h}$ (Table 3). This finding suggested that the addition of pyruvate attenuated the gold cytotoxic effect.

\subsection{Network analysis}

To better understand the key regulated biological processes occurring in A2780/S cell line after Aubipyc treatment, bioinformatics analysis to the list of identified proteins was carried out. The network analysis used is the web-based tool for the interpretation of experimentally derived protein lists in the context of a global PPI network PPI Spider $[38,50]$. We put in the same analysis all the identified proteins listed in Table 2. To start the analysis, we uploaded all these identified proteins, corresponding to 63 unique proteins and we selected H. sapiens as organism. In Fig. 8 (obtained by Cytoscape: http:// www.cytoscape.org/) there is a reported graphical illustration of the protein-protein interaction network created by the analysis. The table reported in Fig. 8 summarizes the results for this submission using the PPI Spider tool. In the table, the models' definition is also shown which specifies the maximal allowed distance between two input proteins connected (D1 means directly connected, D2 one intermediate is allowed), the number of input proteins covered by the system, and the corresponding significance of the best inferred model. Model D1 ( $p$-value $<0.005)$ covers 8 proteins of the 63 submitted to the 


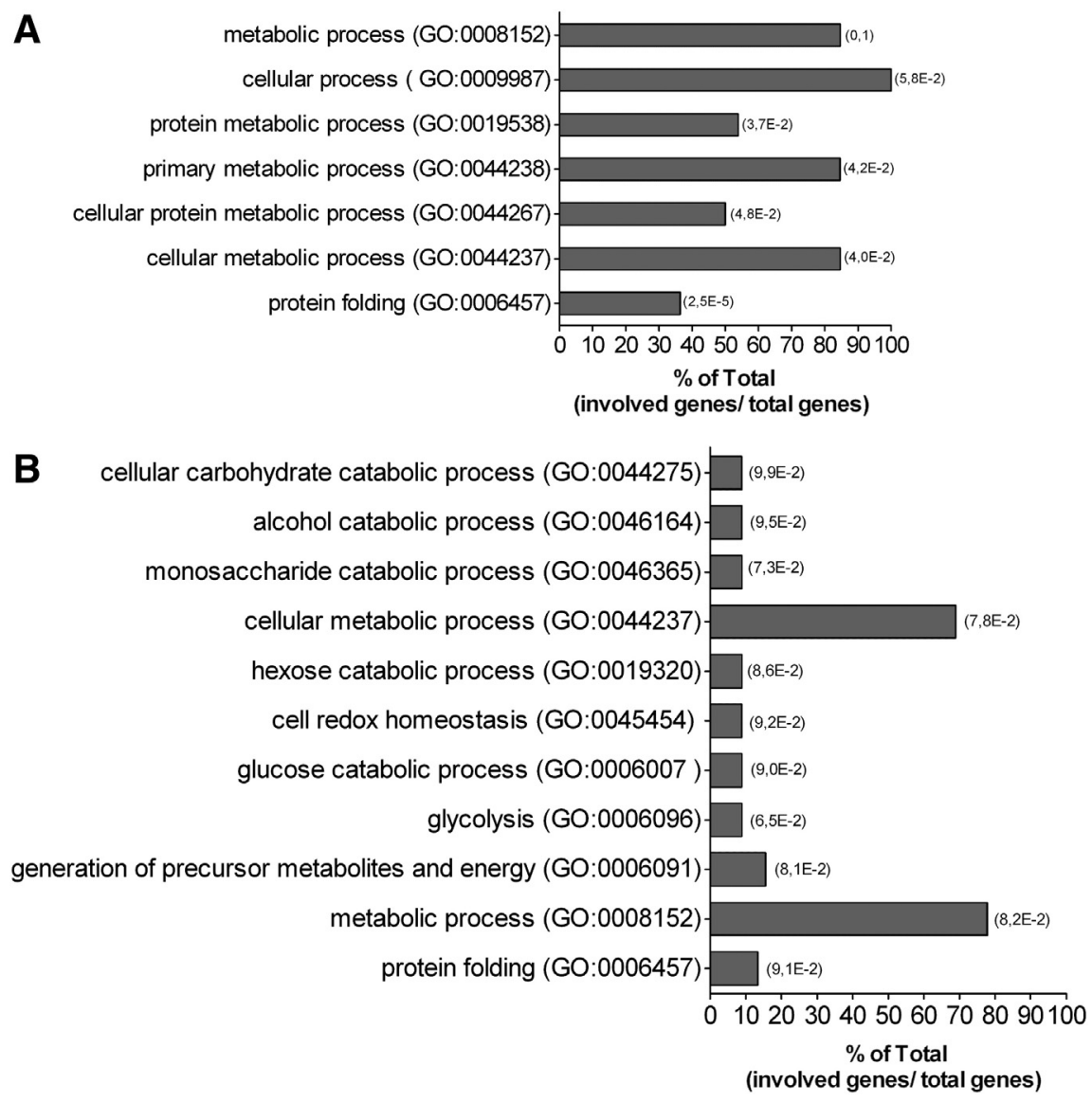

Fig. 4 - Functional GO Biological Process (BP) terms enrichment. GO BP terms statistically over-represented by the up-regulated (A) and the down-regulated (B) protein spots were achieved using the web-accessible program Database Annotation Visualization and Integrated Discovery version 6.7 (DAVID, http://david.abcc.ncifcrf.gov/home.jsp). The values in brackets are the $p$-values after Benjamini correction of each BP term. Detailed composition and statistical parameters of these GO terms were reported in Table S2.

analysis. These proteins are displayed in the square of Fig. 8 and they include 6 subunits of T-complex protein 1 family, the mitochondrial inner membrane protein (IMMT, Q16891) and the cleavage stimulation factor subunit 2 (CSTF2, P33240). The inferred network model D2 ( $p$-value $<0.005)$ includes 45 of the identified proteins and 31 new proteins representing common interactors able to connect most of the proteins in the input list. These 31 intermediate nodes are represented as triangles in the network of Fig. 8. We focused on proteins which represent the main nodes of this network. The interconnected proteins in the network D1 are linked to the network D2 by the intermediate node RAF1. It is a serine/threonine-protein kinase that acts as a regulatory link between the membrane-associated Ras GTPases and the MAPK/ERK cascade, thus playing an important role in the control of gene expression involved in the cell division cycle, apoptosis, cell differentiation, and cell migration. In the network D2, HSP60 mitochondrial (P10809) represents a central node. It interacts with 5 intermediates not identified by the proteomic analysis (RAF1, SIRT1, SIRT3, PPP2R-1B, and SPG20). The proteins SIRT1 and SIRT3 are deacetylases belonging to the sirtuin family. Sirt1 participates in the coordination of several functions such as cell cycle, response to DNA damage, metabolism, apoptosis and autophagy. SIRT3 is a NAD-dependent protein deacetylase which activates mitochondrial target proteins such as ACSS1, IDH2 and GDH contributing to the regulation of the cellular energy metabolism. In our network, Sirt3 is connected to the identified mitochondrial subunit alpha of ATP synthase (P25705). The central node HSP60 also interacts with the protein PPP2R-1B that belongs to the phosphatase $2 \mathrm{~A}$ regulatory subunit $\mathrm{A}$ family involved in the positive regulation of extrinsic apoptotic signaling pathway. Among the intermediate nodes connected to $P P P 2 R-1 B$, we found proteins that function in folding, transcription regulation, cell cycle regulation and energy metabolism. We also found two intermediates involved in signal transduction such as MAPK13 and MAP3K3. MAPK13 is one of the four p38 MAPKs which plays an important role in the cellular responses to proinflammatory cytokines or physical stress leading to direct activation of transcription factors such as ELK1 and ATF2. Moreover it mediates activation of the NF-kappa-B, AP1 and DDIT3 transcriptional regulators REF. Concerning SPG20 (spartin), the last intermediate node interconnected to HSP60 mitochondrial, it is involved in many cellular processes and associates with several intracellular 
A

\begin{tabular}{|c|c|c|c|c|}
\hline Category & Pathway & Involved Genes & $p$-value & Benjamin \\
\hline BIOCARTA & Glycolysis & $\begin{array}{c}\text { Enolase1, alpha (P06733); } \\
\text { Glyceraldehyde-3-phosphate } \\
\text { dehydrogenase (P04406); } \\
\text { Phosphoglycerate kinase 1 (P00558) }\end{array}$ & $1,1 \mathrm{E}-3$ & $9,8 \mathrm{E}-3$ \\
\hline KEGG_PATHWAY & $\begin{array}{c}\text { Glycolysis/ } \\
\text { Gluconeogenesis }\end{array}$ & $\begin{array}{c}\text { Enolase1, alpha (P06733); } \\
\text { Glyceraldehyde-3-phosphate } \\
\text { dehydrogenase (P04406); } \\
\text { Phosphoglycerate kinase 1 (P00558); } \\
\text { Pyruvate kinase, isozymes M1/M2 } \\
\text { (P14618) }\end{array}$ & $2,7 \mathrm{E}-3$ & $1,0 \mathrm{E}-1$ \\
\hline
\end{tabular}

B

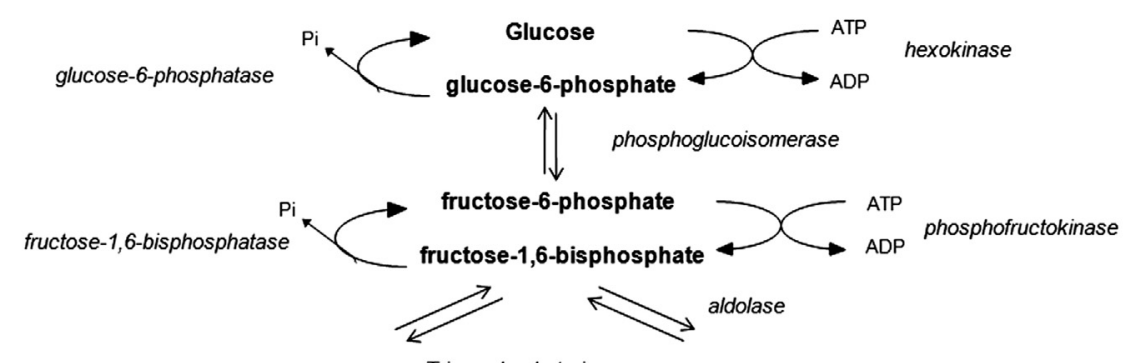

dihydroxyacetone phosphate Triose phophate isomerase glyceraldehyde-3-phosphate

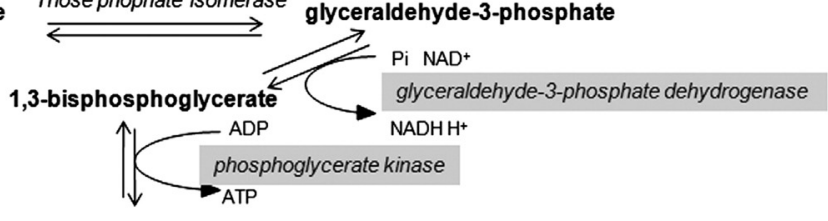

3-phosphoglycerate

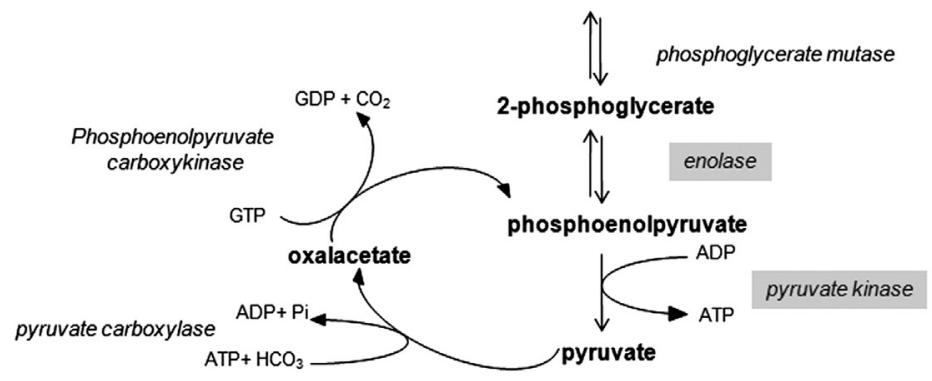

Fig. 5 - Glycolysis pathway enrichment. (A) Biocarta and KEGG pathway results obtained using the down-regulated protein list. The analysis was performed by DAVID and accepting a $p$-value $<0.1$ after Benjamini correction. (B) Graphical representation of glycolysis pathway. The dashed areas denote the identified proteins involved in the glycolysis pathway enrichment.

organelles, including mitochondria [51]. This intermediate is connected through the stress-70 protein mitochondrial (P38646) to the identified Calreticulin (P27797). This protein represents another important node of the network D2. Calreticulin interacts with four new intermediate nodes: TAP1, ELF3, PAK2, and REL which play different biological roles. TAP1 has a peptide transport activity whereas ELF3 is involved in transcription regulation. PAK2, a serine/threonine protein kinase, plays a role in: cytoskeleton regulation, cell motility, cell cycle progression, apoptosis or proliferation. It acts as a downstream effector of the small GTPases CDC42 and RAC1. Interestingly, among the intermediate nodes connected to PK2, we found two proteins (TAB1, RIPK2) that are involved in the positive regulation of I-kappaB kinase/NF-kappaB cascade. REL, the last interactor of Calreticulin, is involved in the positive regulation of I-kappaB kinase/NF-kappaB cascade. Among the intermediate nodes connected to REL, we found few proteins related to cell growth, survival and apoptosis.
Key proteins of this pathway, TOB1, DIDO1 and TRAF1, regulate the sensitivity of cells to anti-proliferative and apoptotic stimulus [52-54]. Moreover, REL is linked through the identified glycolytic enzyme GAPDH (P04406), with the intermediate node DHRS2 (dehydrogenase/reductase SDR family member 2, mitochondrial) a mitochondrial protein with a functional role in promoting growth inhibition. In turn, this protein is linked to the identified mitochondrial proteins Prohibitin (P35232) and voltage-dependent anion channel 2 (VDAC2, P45880). Fusion and fission maintain the functional integrity of mitochondria and Prohibitin forms large ring complexes in the inner membrane. It inhibits DNA synthesis and it has a role in regulating cell proliferation and mitochondrial respiration activity [55]. The VDAC family of proteins are considered as the main pathway for metabolite diffusion across the mitochondrial outer membrane and are involved in the BCL2 mitochondrial apoptotic pathway. VDAC and Prohibitin were found associated with an Alzheimer's 

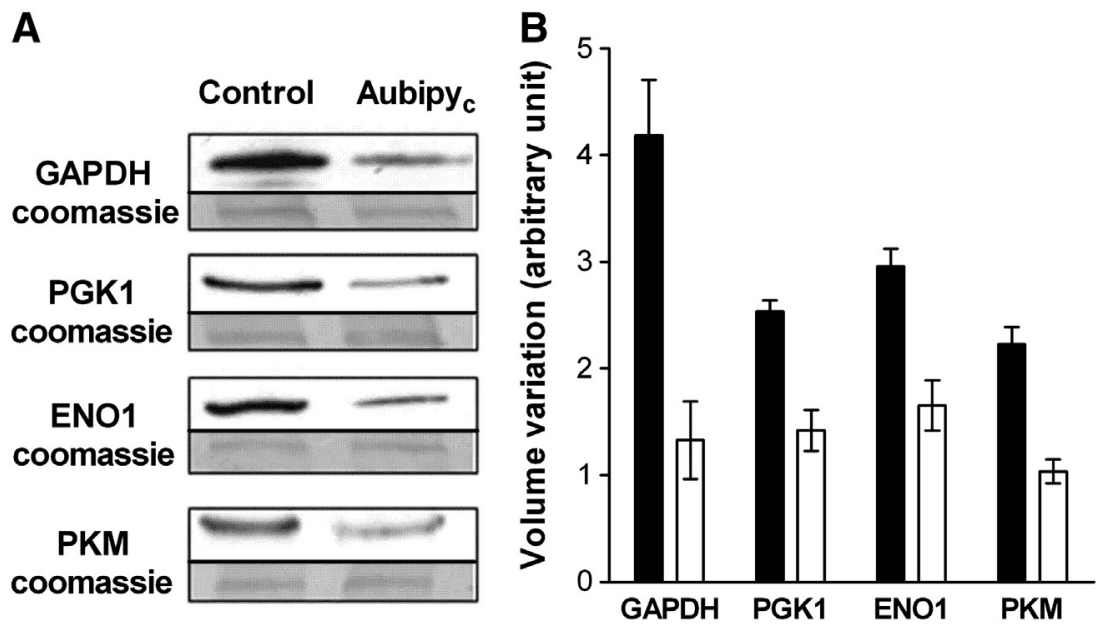

Fig. 6 - Validation of proteomic results by Western blot. Western blot was probed with antibodies against GAPDH, PGK1, ENO1 and PKM proteins identified by proteomic analysis. The intensity of immune-stained bands was normalized with the total protein intensities measured from the same blot stained with Coomassie brilliant blue. (A) Representative Western blot image of A2780/S cells treated for $24 \mathrm{~h}$ with Aubipy $\mathrm{y}_{c}$ concentration corresponding to its 72-h-exposure IC 50 dose (3.1 $\left.\mu \mathrm{M}\right)$. (B) In the histogram, for each protein, the mean value \pm SD of Western blot signals, expressed as arbitrary units (black bars: control cells; white bars: Aubipyc-treated cells), is reported. For each protein, three biological replicates were performed. The two-tailed non-paired Student's-t-test was carried out using Graphpad Prism 4. The amount of each protein was statistically different between control and treated cells ( $p$-value $<0.05)$.

disease accelerator which, by an alteration of the membrane environment, induces a reversible mitochondrial phenotype similar to that found in the disease [56].

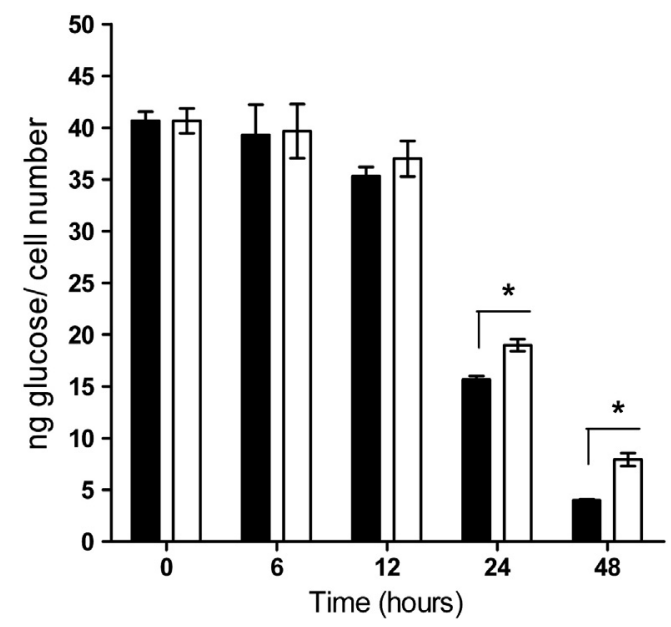

Fig. 7 - Glucose assay. A2780/S cells were treated for $48 \mathrm{~h}$

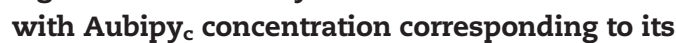
72-h-exposure IC $_{50}$ dose $(3.1 \mu \mathrm{M})$. Glucose level was assessed in $1 \mathrm{~mL}$ of medium supernatant immediately after the addition of Aubipyc (time 0 ) and after 6, 12, 24 and $48 \mathrm{~h}$. For each time point, three biological replicates were performed. The two-tailed non-paired Student's-t-test was carried out using Graphpad Prism 4. In the histogram, the mean value \pm SD of the glucose amount expressed as $\mathrm{ng}$ glucose/cell number (black bars: control cells; white bars: Aubipy $_{c}$-treated cells) is reported. A $p$-value $<0.05$ was considered statistically significant (*).

\section{Discussions}

The main goal of the present investigation was to examine the cytotoxic effects and the associated proteomic alterations of the representative gold compound namely Aubipy ${ }_{c}$ on the A2780/S cancer cell line in the attempt to delineate its likely mode of action. We carried out a comparative proteomic study using 2-DE coupled with mass spectrometry. The results pointed out 95 differentially expressed protein spots following Aubipyc treatment. We successfully identified 87 of these protein spots and among them, in treated cells, 29 resulted up-regulated and 58 down-regulated. These proteins play specific roles in a variety of biological processes. Most of them belong to functional classes i.e. stress response and chaperones, protein synthesis, metabolism and cell redox homeostasis and cytoskeleton and cell structure.

In order to understand the biological meaning behind the list of identified proteins, we analyzed separately the up- and down-regulated proteins by the web-accessible program DAVID. This program provides information about the GO terms enriched by a dataset of proteins or genes. Processing the up-regulated proteins we found statistically enriched GO

Table 3-Effect of extra pyruvate addition in the culture medium on antiproliferative activity of Aubipyc against A2780/s cell line.

\begin{tabular}{cccc} 
Compound & \multicolumn{2}{c}{ A2780/S IC50 $[\mu \mathrm{M}] \pm \mathrm{SE}$} & $p$-value \\
\cline { 2 - 3 } & No extra pyruvate & $+1 \mathrm{mM}$ pyruvate & \\
\hline $\begin{array}{c}\text { Aubipy }_{\mathrm{c}} \\
\mathrm{n}\end{array}$ & $3.1 \pm 0.1$ & $8.4 \pm 0.4$ & 0.0017 \\
\hline
\end{tabular}

$\mathrm{n}$, number of experiments; SE, standard error. 


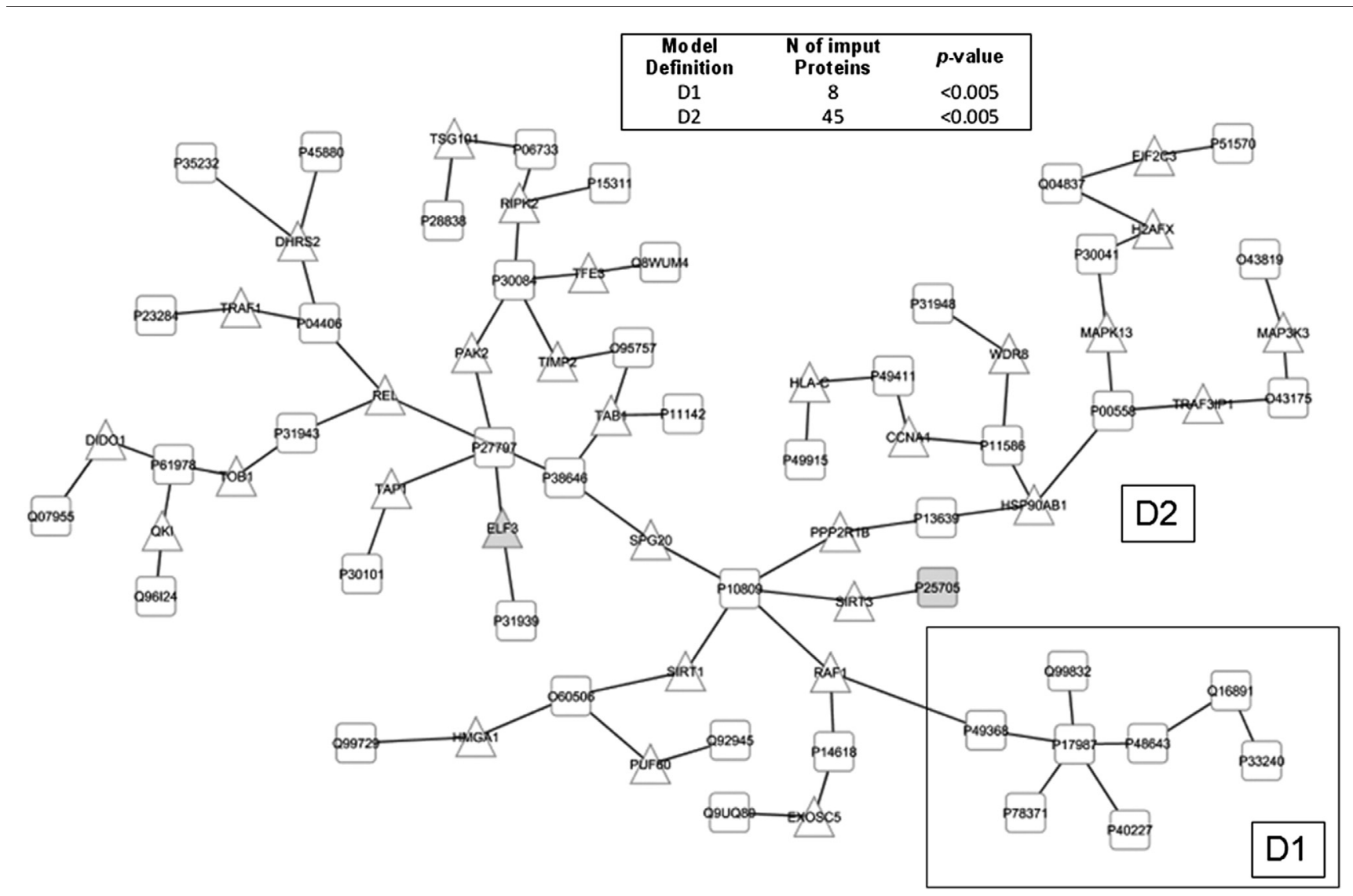

Fig. 8 - PPI Spider results by Bioprofiling.de. The network represents the interactome in which all the identified proteins are involved.

BP terms involved in 'protein folding' and 'protein metabolic process'. Most of the proteins involved in this enrichment belong to the functional class 'stress response and chaperones'. We found several subunits of T-complex protein 1 (CCT3, CCT5, TCP1, CCT6A, CCT7) and different members of the heat shock family such as HSP60 mitochondrial, Stress-70 protein mitochondrial and heat shock $70 \mathrm{kDa}$ protein $4 \mathrm{~L}$ and heat shock cognate $71 \mathrm{kDa}$ protein. Several studies reported an increase of Hsp expression upon exposure to anticancer agents. These chaperones may participate in the stress response to drug-induced damage [57]. Experimental evidence supports the dual capability of anticancer drugs to act as lethal agents for tumor cells as well as to induce the adaptive stress response in the neoplastic environment. Anticancer drugs activate cell death programs [58] and modulate expression of genes that are essential for drug resistance [59]. In fact, in addition to their normal housekeeping character in folding proteins, the frequently protective induction of HSPs in response to stress and their role in the regulation of death signals are well recognized [60]. The HSPs are implicated in both the effectiveness and the tolerance to chemotherapy [60]. T-complex protein 1 subunits were already found to be involved in the process of cisplatin resistance by Castagna et al. [61]. It is noteworthy that some of these chaperones, such as TCP1, heat shock $70 \mathrm{kDa}$ protein $4 \mathrm{~L}$ and heat shock cognate $71 \mathrm{kDa}$ protein, resulted both increase and decrease in protein abundance. This apparent discrepancy occurred because we found a decrease in the amount of spots corresponding to the full length protein with a concomitant increase in the amount of protein spots with a lower Mr. This may be explain with the presence of protein fragmentation due to gold treatment or with the presence of different protein species.

Analyzing the down- regulated proteins list, we statistically enriched GO BP terms associated with metabolism and energy production ('metabolic process', 'generation of precursor metabolites and energy', and 'glycolysis'). Most of the proteins involved in this enrichment are metabolic enzymes such as the glycolytic enzymes PKM, GAPDH, ENO1, and PGK1. We also found enzymes of different metabolic processes such as ATP metabolism, galactose metabolism, retinol metabolism, lipid and ketone metabolism, amino-acid and protein metabolism. Another GO BP term enriched within the list of down-regulated proteins was 'cell redox homeostasis'. The mitochondrial SCO2 homolog, peroxiredoxin-6, protein disulfide-isomerase A3 and the cytoplasmic thioredoxin reductase 1 were clustered in this enrichment. An interesting finding of this functional analysis dealt with the enrichment of GO terms associated with glucose metabolism. In line with this result, the down-regulated protein also statistically enriched the pathway 'glycolysis'. This data was also confirmed by Western blot analysis in which the level of the glycolytic enzymes PKM, GAPDH, ENO1, and PGK1 were

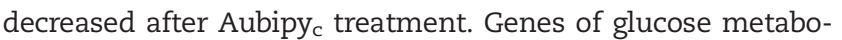
lism have been reported to be ubiquitously over-expressed in cancer cells [62]. Many researchers have shown that tumors 
prefer glycolysis to form ATP. The glycolytic shift in tumor cells compensates for mitochondrial dysfunction and also provides resistance to apoptosis. Moreover, these metabolic alterations are responsible for chemoresistance in cancer therapy. Glyceraldehyde-3-phosphate dehydrogenase and alpha enolase seem to be relevant in the acquisition of drug resistance in cancer cell lines, due to their transcriptional regulation activity more than their function in glycolysis [63]. Therefore, the combination of anticancer chemotherapeutics and metabolic modulators could be a promising strategy to overcome chemoresistance [64]. Moreover, we found markedly decreased the amount of an isocitrate dehydrogenase

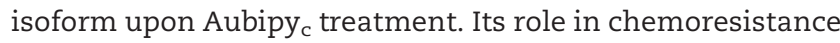
still remains to be elucidated, however it was already found to be involved in drug resistance in ovarian and other types of cancer $[65,66]$.

In conclusion the proteomic and bioinformatic results underline a potential negative effect of Aubipyc treatment on glucose metabolism that might lead to the activation of a stress response mediated by chaperones and stress response proteins. We also supported this hypothesis by the assessment of the glucose level in the culture medium after gold treatment. The results revealed that after 24 and 48 h, A2780/S treated cells displayed a higher amount of glucose with respect to controls indicating a lower consumption of this sugar. Moreover, the antiproliferative activity of Aubipy ${ }_{c}$ was reduced by the addition of extra pyruvate in the culture medium. This indicates that pyruvate can overcome the slowdown of glycolytic flux and

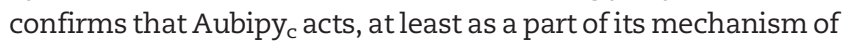
action, affecting glycolytic pathway.

The variations in protein expressions pointed out by our proteomic analysis could be an indirect consequence of other changes affecting less expressed and non detectable proteins. To identify these proteins we performed a pathway analysis using the global PPI Spider network. The network includes 45 of the 87 proteins identified in this study and 31 new intermediate proteins, whose expression level could be influenced by the Aubipy ${ }_{c}$ treatment. Several identified proteins belong to the functional class 'chaperones and stress response' such as the central node of the network HSP60 mitochondrial, HSP90AB1, stress-70 mitochondrial protein, HSP704L and STIP1. We found new interactors involved in transcription regulation and mRNA splicing such as EIF2C3, TFES, ELF3, HMGA1 and PUF60. These findings agree with the GO functional analysis supporting an involvement of the biological process 'protein folding' and 'protein synthesis' in Aubipyc cytotoxicity response. It is worthwhile to note that most of the 31 new intermediate nodes are involved in the functional classes 'cell cycle and apoptosis', and 'DNA replication and repair'. Among the proteins implicated in the apoptotic process, we found RAF1, SIRT1, PPP2R-1B, PAK2, REL, TRAF1, TOB1, DID01, Prohibitin, PDCD6IP (Q8WUM4) and VADAC2 $[67,68]$. This datum strongly correlates to the recent studies on the mechanisms through which Aubipy ${ }_{c}$ causes cell death. Indeed, it was found that this gold compound induces extensive apoptotic cell death [21]. Due to the fact that Aubipyc is a strong inhibitor of mitochondrial thioredoxin reductase [23], it was proposed that apoptotic cell death might arise from direct mitochondrial damage. In line with this hypothesis, we found several proteins related to the mitochondrial functionality such as the NAD+-dependent deacetylase SIRT3 [69], Prohibitin, VADC2 and DHRS2. Interestingly, we found proteins associated with the GO biological process 'I-kappaB kinase/NF-kappaB cascade' such as REL, TRAF1, MAP3K3, RIPK2and TAB1. This pathway has been associated to other metallo-drugs. It has been shown that, in cervical carcinoma cells, cisplatin treatment-induced NF-kappaB down-regulation is mediated by TRAF2, and it triggers the membrane death receptor/mitochondria-mediated apoptotic pathway [25]. Furthermore, the activation of nuclear factor kappaB (NF-kappaB) contributes to drug resistance in pancreatic carcinoma and it was demonstrated that pretreatment of pancreatic carcinoma cells with genistein, that down-regulates NF-kappaB activity, enhances the apoptosis-inducing effect of cisplatin, leading to greater antitumor activity in vivo [70]. Moreover, anti-rheumatic gold compounds, such as auranofin, have been shown to inhibit NF- $\mathrm{B}$ activation by blocking $\mathrm{I}_{\kappa} \mathrm{B}$ kinase (IKK) activity.

In conclusion the network analysis highlighted the involvement of proteins associated with biological processes, as protein folding and synthesis, apoptosis and cellular prolifer-

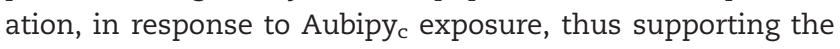
proteomic results. Moreover, this analysis led to the identification of proteins associated with NF-kB pathway. Some of these proteins may be further investigated to better identify and characterize the cellular perturbations induced by Aubipy $_{\text {. }}$

\section{Conclusions}

In summary, we have reported here the first proteomic analysis regarding Aubipy c cytotoxicity on A2780/S cell line.

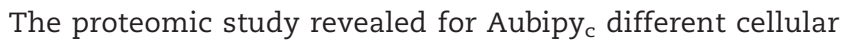
alterations with respect to cisplatin as well as to other gold compound such as auranofin. Remarkably, from our bioinformatic and functional analysis, it emerged quite clearly

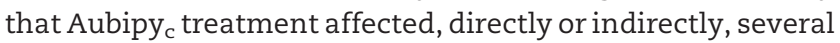
glycolytic enzymes leading to a possible down-regulation of glucose metabolism. However, it should be kept in mind that this work is just a first exploration of the mechanisms underlying the cytotoxic effects of Aubipyc. Further study is actually required to clarify the specific role exerted by the identified proteins and their corresponding pathways in cell response to drug-induced damage. Additional analyses are needed to demonstrate if Aubipyc is able to bind directly these proteins or at least some of them. At present, we are performing a parallel proteomic study on the A2780/R cell

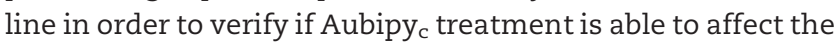
expression level of proteins associated to cisplatin resistance. This study might further confirm the mechanistic results achieved with the present investigation.

Supplementary data to this article can be found online at http://dx.doi.org/10.1016/j.jprot.2014.03.032.

\section{Transparency Document}

The Transparency document associated with this article can be found, in the online version. 


\section{Acknowledgments}

We gratefully acknowledge Beneficentia Stiftung Foundation (Vaduz, Liechtenstein) BEN 2013/38, AIRC (IG-12085) and COST Action CM1105 for the generous financial support. The authors wish to thank Maria Agostina Cinellu of the Department of Chemistry and Pharmacy, University of Sassari, for the gift of an Aubipy sample. $^{2}$

\section{R E F E R E N C E S}

[1] Wang D, Lippard SJ. Cellular processing of platinum anticancer drugs. Nat Rev Drug Discov 2005;4:307-20.

[2] Kelland L. The resurgence of platinum-based cancer chemotherapy. Nat Rev Cancer 2007;7:573-84.

[3] Garbutcheon-Singh KB, Grant MP, Harper BW, Krause-Heuer AM, Manohar M, Orkey N, et al. Transition metal based anticancer drugs. Curr Top Med Chem 2011;11:521-42.

[4] Tiekink ERT. Gold derivatives for the treatment of cancer. Crit Rev Oncol Hematol 2002;42:225-48.

[5] Messori L, Marcon G, Orioli P, Fontani M, Zanello P, Bergamo A, et al. Molecular structure, solution chemistry and biological properties of the novel [ImH] [trans $-\operatorname{lrCl}(4)(\mathrm{Im})(\mathrm{DMSO})],(\mathrm{I})$ and of the orange form of [(DMSO)(2)H][trans-IrCl4 (DMSO)(2)], (II), complexes. J Inorg Biochem 2003;95:37-46.

[6] Nobili S, Mini E, landini I, Gabbiani C, Casini A, Messori L. Gold compounds as anticancer agents: chemistry, cellular pharmacology, and preclinical studies. Med Res Rev 2010;30:550-80.

[7] Sun RWY, Che CM. The anti-cancer properties of gold(III) compounds with dianionic porphyrin and tetradentate ligands. Coord Chem Rev 2009;253:1682-91.

[8] Gabbiani C, Casini A, Messori L. Gold(III) compounds as anticancer drugs. Gold Bull 2007;40:73-81.

[9] Messori L, Abbate F, Marcon G, Orioli P, Fontani M, Mini E, et al. Gold(III) complexes as potential antitumor agents: solution chemistry and cytotoxic properties of some selected gold(III) compounds. J Med Chem 2000;43:3541-8.

[10] Ronconi L, Giovagnini L, Marzano C, Bettio F, Graziani R, Pillon G, et al. Gold dithiocarbamate derivatives as potential antineoplastic agents: design, spectroscopic properties, and in vitro antitumor activity. Inorg Chem 2005;44:1867-81.

[11] Che CM, Sun RWY, Yu WY, Ko CB, Zhu NY, Sun HZ. Gold(III) porphyrins as a new class of anticancer drugs: cytotoxicity, DNA binding and induction of apoptosis in human cervix epitheloid cancer cells. Chem Commun 2003:1718-9.

[12] Coronnello M, Mini E, Caciagli B, Cinellu MA, Bindoli A, Gabbiani C, et al. Mechanisms of cytotoxicity of selected organogold(III) compounds. J Med Chem 2005;48:6761-5.

[13] Messori L, Marcon G, Cinellu MA, Coronnello M, Mini E, Gabbiani C, et al. Solution chemistry and cytotoxic properties of novel organogold(III) compounds. Bioorg Med Chem 2004;12:6039-43.

[14] Gabbiani C, Casini A, Messori L, Guerri A, Cinellu MA, Mighetti $G$, et al. Structural characterization, solution studies, and DFT calculations on a series of binuclear gold(III) oxo complexes: relationships to biological properties. Inorg Chem 2008;47:2368-79.

[15] Shaw CF, Cohen MI, Barnhardt R. Inspiratory-modulated neurons of the rostrolateral pons - effects of pulmonary afferent input. Brain Res 1989;485:179-84.
[16] Messori L, Orioli P, Tempi C, Marcon G. Interactions of selected gold(III) complexes with calf thymus DNA. Biochem Biophys Res Commun 2001;281:352-60.

[17] Barnard PJ, Berners-Price SJ. Targeting the mitochondrial cell death pathway with gold compounds. Coord Chem Rev 2007;251:1889-902.

[18] Rigobello MP, Scutari G, Boscolo R, Bindoli A. Induction of mitochondrial permeability transition by auranofin, a gold(I)-phosphine derivative. Br J Pharmacol 2002;136:1162-8.

[19] Bindoli A, Rigobello MP, Scutari G, Gabbiani C, Casini A, Messori L. Thioredoxin reductase: a target for gold compounds acting as potential anticancer drugs. Coord Chem Rev 2009;253:1692-707.

[20] Jeon KI, Byun MS, Jue DM. Gold compound auranofin inhibits I kappa B kinase (IKK) by modifying Cys-179 of IKK beta subunit. Exp Mol Med 2003;35:61-6.

[21] Marcon G, Carotti S, Coranello M, Messori L, Mini E, Orioli P, et al. Gold(III) complexes with bipyridyl ligands: solution chemistry, cytotoxicity, and DNA binding properties. J Med Chem 2002;45:1672-7.

[22] Gabbiani C, Cinellu MA, Maiore L, Massai L, Scaletti F, Messori L. Chemistry and biology of three representative gold(III) compounds as prospective anticancer agents. Inorg Chim Acta 2012;393:115-24.

[23] Rigobello MP, Messori L, Marcon G, Cinellu MA, Bragadin M, Folga A, et al. Gold complexes inhibit mitochondrial thioredoxin reductase: consequences on mitochondrial functions. J Inorg Biochem 2004;98:1634-41.

[24] Wang Y, Chiu J-F. Proteomic approaches in understanding action mechanisms of metal-based anticancer drugs. Metal-Based Drugs 2008:716329.

[25] Yim EK, Lee KH, Kim CJ, Park JS. Analysis of differential protein expression by cisplatin treatment in cervical carcinoma cells. Int J Gynecol Cancer 2006;16:690-7.

[26] Yao Y, Jia XY, Tian HY, Jiang YX, Xu GJ, Qian QJ, et al. Comparative proteomic analysis of colon cancer cells in response to oxaliplatin treatment. Biochim Biophys Acta 2009;1794:1433-40.

[27] Wang Y, He QY, Che CM, Chiu JF. Proteomic characterization of the cytotoxic mechanism of gold (III) porphyrin 1a, a potential anticancer drug. Proteomics 2006;6:131-42.

[28] Magherini F, Modesti A, Bini L, Puglia M, Landini I, Nobili S, et al. Exploring the biochemical mechanisms of cytotoxic gold compounds: a proteomic study. J Biol Inorg Chem 2010;15:573-82.

[29] Guidi F, Landini I, Puglia M, Magherini F, Gabbiani C, Cinellu $\mathrm{MA}$, et al. Proteomic analysis of ovarian cancer cell responses to cytotoxic gold compounds. Metallomics 2012;4:307-14.

[30] Guidi F, Puglia M, Gabbiani C, Landini I, Gamberi T, Fregona D, et al. 2D-DIGE analysis of ovarian cancer cell responses to cytotoxic gold compounds. Mol Biosyst 2012;8:985-93.

[31] Skehan P, Storeng R, Scudiero D, Monks A, McMahon J, Vistica $D$, et al. New colorimetric cytotoxicity assay for anticancer-drug screening. J Natl Cancer Inst 1990;82:1107-12.

[32] Wessel D, Flugge A. A method for the quantitative recovery of protein in dilute solution in the presence of detergents and lipids. Anal Biochem 1984;138:141-3.

[33] Hochstrasser DF, Harrington MG, Hochstrasser AC, Miller MJ, Merril CR. Methods for increasing the resolution of two-dimensional protein electrophoresis. Anal Biochem 1988;173:424-35.

[34] Candiano G, Bruschi M, Musante L, Santucci L, Ghiggeri GM, Carnemolla B, et al. Blue silver: a very sensitive colloidal Coomassie G-250 staining for proteome analysis. Electrophoresis 2004;25:1327-33.

[35] Karp NA, Spencer M, Lindsay H, O'Dell K, Lilley KS. Impact of replicate types on proteomic expression analysis. J Proteome Res 2005;4:1867-71. 
[36] Hunt SM, Thomas MR, Sebastian LT, Pedersen SK, Harcourt RL, Sloane AJ, Wilkins MR. Optimal replication and the importance of experimental design for gel-based quantitative proteomics. Proteome Res 2005;4:809-19.

[37] Antonov AV. BioProfiling.de: analytical web portal for high-throughput cell biology. Nucleic Acids Res 2011;39: W323-7.

[38] Antonov AV, Dietmann S, Rodchenkov I, Mewes HW. PPI spider: a tool for the interpretation of proteomics data in the context of protein-protein interaction networks. Proteomics 2009;9:2740-9.

[39] Masoudi-Nejad A, Ansariola M, Kashani ZR, Salehzadeh-Yazdi A, Khakabimamaghani S. CytoKavosh: a cytoscape plug-in for finding network motifs in large biological networks. PLoS One 2012;7:e43287.

[40] Casini A, Kelter G, Gabbiani C, Cinellu MA, Minghetti G, Fregona D, et al. Chemistry, antiproliferative properties, tumor selectivity, and molecular mechanisms of novel gold(III) compounds for cancer treatment: a systematic study. J Biol Inorg Chem 2009;14:1139-49.

[41] Storey JD, Tibshirani R. Statistical significance for genome wide studies. Proc Natl Acad Sci U S A 2003;100:9440-5.

[42] Karp NA, Lilley KS. Design and analysis issues in quantitative proteomics studies. Proteomics 2007;1:42-50.

[43] Di Michele M, Della Corte A, Cicchillitti L, Del Boccio P, Urbani A, Ferlini C, et al. A proteomic approach to paclitaxel chemoresistance in ovarian cancer cell lines. Biochim Biophys Acta 2009;1794:225-36.

[44] Sun W, Xing B, Sun Y, Du X, Lu M, Hao C, et al. Proteome analysis of hepatocellular carcinoma by two-dimensional difference gel electrophoresis. Mol Cell Proteomics 2007;6:1798-808.

[45] Huang DW, Sherman BT, Lempicki RA. Systematic and integrative analysis of large gene lists using DAVID bioinformatics resources. Nat Protoc 2009;4:44-57.

[46] Huang DW, Sherman BT, Lempicki RA. Bioinformatics enrichment tools: paths toward the comprehensive functional analysis of large gene lists. Nucleic Acids Res 2009;37:1-13.

[47] Dekker C, Stirling PC, McCormack EA, Filmore H, Paul A, Brost RL, et al. The interaction network of the chaperonin CCT. EMBO J 2008;27:1827-39.

[48] Ott I. On the medicinal chemistry of gold complexes as anticancer drugs. Coord Chem Rev 2009;253:1670-81.

[49] Messori L, Scaletti F, Massai L, Cinellu MA, Gabbiani C, Vergarad A, et al. The mode of action of anticancer gold-based drugs: a structural perspective. Chem Commun 2013;49:10100-2.

[50] Gamberi T, Magherini F, Bini L, Messori L, Gabbiani C, Pietrovito L, et al. New insights into the molecular mechanisms of selected anticancer compounds through bioinformatic analysis of proteomic data. J Proteomics Bioinform 2013:S6-006.

[51] Joshi DC, Bakowska JC. SPG20 protein spartin associates with cardiolipin via its plant-related senescence domain and regulates mitochondrial $\mathrm{Ca}^{2+}$ homeostasis. PLoS One 2011;6: e19290.

[52] Kundu J, Wahab SM, Kundu JK, Choi YL, Erkin OC, Lee HS, et al. Tob1 induces apoptosis and inhibits proliferation, migration and invasion of gastric cancer cells by activating Smad4 and inhibiting $\beta$-catenin signaling. Int J Oncol 2012;41:839-48.

[53] Braig S, Bosserhoff AK. Death inducer-obliterator 1 (Dido1) is a BMP target gene and promotes BMP-induced melanoma progression. Oncogene 2013;32:837-48.
[54] Choudhary S, Kalita M, Fang L, Patel KV, Tian B, Zhao Y, et al. Inducible tumor necrosis factor (TNF) receptor-associated factor-1 expression couples the canonical to the non-canonical NF- $\kappa$ B pathway in TNF stimulation. J Biol Chem 2013;288:14612-23.

[55] Merkwirth C, Martinelli P, Korwitz A, Morbin M, Brönneke HS, Jordan SD, et al. Loss of prohibitin membrane scaffolds impairs mitochondrial architecture and leads to tau hyperphosphorylation and neurodegeneration. PLoS Genet 2012;8:e1003021.

[56] Bettayeb K, Oumata N, Zhang Y, Luo W, Bustos V, Galons H, et al. Small-molecule inducers of $A \beta-42$ peptide production share a common mechanism of action. FASEB J 2012;26:5115-23.

[57] Tiligada E. Chemotherapy: induction of stress responses. Endocr Relat Cancer 2006;13:S115-24.

[58] Herr I, Debatin KM. Cellular stress response and apoptosis in cancer therapy. Blood 2001;98:2603-14.

[59] Kohno K, Uchiumi T, Niina I, Wakasugi T, Igarashi T, Momii Y, et al. Transcription factors and drug resistance. Eur J Cancer 2005;41:2577-86

[60] Calderwood SK, Khaleque MA, Sawyer DB, Ciocca DR. Heat shock proteins in cancer: chaperones of tumorigenesis. Trends Biochem Sci 2006;31:164-72.

[61] Castagna A, Antonioli P, Astner H, Hamdan M, Righetti SC, Perego $\mathrm{P}$, et al. A proteomic approach to cisplatin resistance in the cervix squamous cell carcinoma cell line A431. Proteomics 2004;4:3246-67.

[62] Altenberg B, Greulich KO. Genes of glycolysis are ubiquitously overexpressed in 24 cancer classes. Genomics 2004;84:1014-20.

[63] Mori-Iwamoto S, Kuramitsu Y, Ryozawa S, Mikuria K, Fujimoto M, Maehara S, et al. Proteomics finding heat shock protein 27 as a biomarker for resistance of pancreatic cancer cells to gemcitabine. Int J Oncol 2007;31:1345-50.

[64] Suh DH, Kim M-K, No JH, Chung HH, Song YS. Metabolic approaches to overcoming chemoresistance in ovarian cancer. Ann N Y Acad Sci 2011;1229:53-60.

[65] Yan XD, Pan LY, Yuan Y, Lang JH, Mao N. Identification of platinum-resistance associated proteins through proteomic analysis of human ovarian cancer cells and their platinum-resistant sublines. J Proteome Res 2007;6:772-80.

[66] Smith L, Welham KJ, Watson MB, Drew PJ, Lind MJ, Cawkwell $\mathrm{L}$. The proteomic analysis of cisplatin resistance in breast cancer cells. Oncol Res 2007;16:497-506.

[67] Marlin JW, Chang Y-WE, Jakobi R. Caspase activation of p21-Activated kinase 2 occurs during cisplatin-induced apoptosis of SH-SY5Y neuroblastoma cells and in SH-SY5Y cell culture models of Alzheimer's and Parkinson's disease. Journal of Cell Death 2010;3:23-32.

[68] Liang XJ, Finkel T, Shen DW, Yin JJ, Aszalos A, Gottesman MM. SIRT1 contributes in part to cisplatin resistance in cancer cells by altering mitochondrial metabolism. Mol Cancer Res 2008;6:1499-506

[69] Ahn BH, Kim HS, Song S, Lee IH, Liu J, Vassilopoulos A, et al. A role for the mitochondrial deacetylase Sirt3 in regulating energy homeostasis. Proc Natl Acad Sci U S A 2008;105:14447-52.

[70] Mohammad RM, Banerjee S, Li Y, Aboukameel A, Kucuk O, Sarkar FH. Cisplatin-induced antitumor activity is potentiated by the soy isoflavone genistein in BxPC-3 pancreatic tumor xenografts. Cancer 2006;106:1260-8. 